\title{
əRegional Energy and Water Budget of a Precipitating Atmosphere over Ocean
}

\author{
Seiji Kato, ${ }^{a}$ Norman G. Loeb, ${ }^{\mathrm{a}}$ John T. Fasullo, ${ }^{\mathrm{b}}$ Kevin E. Trenberth, ${ }^{\mathrm{b}}$ Peter H. Lauritzen, ${ }^{\mathrm{b}}$ \\ Fred G. Rose, ${ }^{c}$ DAvid A. RUTAN, ${ }^{c}$ AND MASAKI SATOH ${ }^{\mathrm{d}}$ \\ ${ }^{a}$ NASA Langley Research Center, Hampton, Virginia \\ ${ }^{\mathrm{b}}$ National Center for Atmospheric Research, Boulder, Colorado \\ ${ }^{\mathrm{c}}$ Science Systems and Applications, Inc., Hampton, Virginia \\ d Atmosphere and Ocean Research Institute, The University of Tokyo, Chiba, Japan
}

(Manuscript received 13 March 2020, in final form 30 December 2020)

\begin{abstract}
Effects of water mass imbalance and hydrometeor transport on the enthalpy flux and water phase on diabatic heating rate in computing the regional energy and water budget of the atmosphere over ocean are investigated. Equations of energy and water budget of the atmospheric column that explicitly consider the velocity of liquid and ice cloud particles, and rain and snow are formulated by separating water variables from dry air. Differences of energy budget equations formulated in this study from those used in earlier studies are that 1) diabatic heating rate depends on water phase, 2) diabatic heating due to net condensation of nonprecipitating hydrometeors is included, and 3) hydrometeors can be advected with a different velocity from the dry-air velocity. Convergence of water vapor associated with phase change and horizontal transport of hydrometeors is to increase diabatic heating in the atmospheric column where hydrometeors are formed and exported and to reduce energy where hydrometeors are imported and evaporated. The process can improve the regional energy and water mass balance when energy data products are integrated. Effects of enthalpy transport associated with water mass transport through the surface are cooling to the atmosphere and warming to the ocean when the enthalpy is averaged over the global ocean. There is no net effect to the atmosphere and ocean columns combined. While precipitation phase changes the regional diabatic heating rate up to $15 \mathrm{~W} \mathrm{~m}^{-2}$, the dependence of the global mean value on the temperature threshold of melting snow to form rain is less than $1 \mathrm{~W} \mathrm{~m}^{-2}$.
\end{abstract}

KEYWORDS: Atmosphere-ocean interaction; Climatology; Diabatic heating; Energy budget/balance

\section{Introduction}

Ocean in situ temperature observations show increasing ocean temperatures (e.g., Lyman and Johnson 2014; Cheng et al. 2017), which is the primary manifestation of Earth's energy imbalance (EEI) derived from top-of-atmosphere (TOA) radiation (von Schuckmann et al. 2016). Ocean temperature changes are driven by increasing anthropogenic forcing, associated with changes in anthropogenic aerosols and greenhouse gases, which in turn drive changes in the flows of energy through the climate system. Ultimately these perturbed flows are known to sequester over $90 \%$ of EEI in the ocean. However, our understanding of the connections between perturbed TOA irradiances, changes in the forms and flows of energy within the atmosphere, and perturbed air-sea exchanges driving ocean warming remain limited. Adequately tracking and accounting for these perturbed flows has been a major challenge for existing observing systems, as uncertainties in energy flow components, particularly at the surface and within the atmosphere, can exceed estimated perturbations driven by climate change by an order of magnitude. This is evident, for example, when satellitederived products are used to close the surface energy budget, as there is a significant discrepancy in the annual global energy balance of 10 to $15 \mathrm{~W} \mathrm{~m}^{-2}$ (Kato et al. 2011; L'Ecuyer et al. 2015). While the cause of the residual is unknown, Loeb et al. (2014) and Kato et al.

¿ Denotes content that is immediately available upon publication as open access.

Corresponding author: Seiji Kato, seiji.kato@nasa.gov
(2016) used satellite-derived radiation, precipitation, sensible heat flux, and atmospheric energy transport data products to identify the tropical ocean as a key region where large discrepancies occur. In addition to the problem of understanding surface radiation budget, the discrepancy of 10 to $15 \mathrm{~W} \mathrm{~m}^{-2}$ creates a significant problem in evaluating climate models with satellite data products. When models are constrained by TOA radiation data products, models that conserve energy and water mass do not match an observed global mean precipitation rate (e.g., Held et al. 2019) because of, in part, the existence of a significant energy balance residual when satellite energy flux products are integrated.

While the total energy is conserved, energy is converted and transferred in various different forms in the atmosphere. Although the regional energy balance in the atmosphere is largely achieved with diabatic heating by precipitation, radiative cooling, and dry static energy divergence by dynamics (Trenberth and Stepaniak 2003a; Kato et al. 2016), all forms need to be considered in closing the energy budget in the atmosphere. Identifying assumptions made in producing data products and accounting for all energy fluxes are the first steps toward closing the regional energy budget when regional energy balance in the atmosphere and surface is analyzed by integrating multiple data products. To include all energy fluxes and identify assumptions that arise when multiple data products are integrated, we formulate an improved set of energy budget equations in this study, aiming toward balancing the energy budget through integrating observational energy flux data products.

Energy budget equations derived in earlier studies (e.g., Peixoto and Oort 1992; Trenberth 1997; Trenberth and Stepaniak 2003b) 
consider moist air but do not express hydrometeors that may have different velocities from the moist air velocity (e.g., precipitation) explicitly. In addition, equations used in earlier studies mostly do not make a distinction between the liquid and ice water phases of hydrometeors. Furthermore, temperature dependence of the enthalpy of vaporization is often ignored in computing global energy budgets (e.g., Trenberth et al. 2009; Stephens et al. 2012). The enthalpy transfer associated with water mass transfer (Mayer et al. 2017; Trenberth and Fasullo 2018) also depends on the phase and temperature of hydrometeors. Assumptions made in formulating earlier energy budget equations are understandable because some of the variables were (and still are) not available as outputs from reanalysis or data products to analyze or diagnose the energy balance. However, that does not preclude work identifying missing energy fluxes and assumptions. Additionally, uncertainties arise when integrating multiple energy data products, especially in converting precipitation rate to diabatic heating rate. In this study, we quantify the effect of temperature dependence on thermodynamic constants and the phase of precipitation when computing diabatic heating rates.

The improved atmospheric energy budget equations developed in this study explicitly account for water vapor, ice, liquid clouds, and precipitation. We use a framework to separate water variables from dry air and to aid identifying assumptions made when multiple energy flux data products are integrated. Separation of precipitations from dry air is necessary to explicitly accounting for their different vertical velocities from dry-air velocity. Although explicitly treating dry air, water vapor, and hydrometeors has been done in earlier work (e.g., Bannon 2002; Satoh 2003), regional energy equations integrated over the atmospheric column explicitly treating dry air, water vapor, and hydrometeors were not derived in earlier studies. We use the velocity of dry air as the reference velocity instead of barycentric velocity and express water vapor and hydrometeor velocities relative to this reference velocity, because dry-air velocity is independent of hydrometeor fallout as precipitation. In addition, because dry-air mass is conserved, we use the dry-air mass as the vertical coordinate instead of total pressure, in accordance with the recent development of National Center for Atmospheric Research Community Earth System Model (Lauritzen et al. 2018). As stated by Lauritzen et al. (2018), the use of dry-air reference velocity and dry-air mass coordinates has an advantage for our purpose. The conservation of energy associated with water is visible in the derivation because all water variables are separated from dry air. We then use improved energy equations to assess the effect of horizontal transport of hydrometeors and enthalpy transport associated with precipitation on the atmospheric energy budget.

Energy and water budget equations are formulated in section 2. Water mass balance and the effect of water mass balance residual and horizontal transport of hydrometeors are assessed in section 3. Enthalpy fluxes at the surface due to water mass fluxes are estimated in section $4 \mathrm{a}$. The effects of water phase and temperature dependence of thermodynamic constants on diabatic heating rates are evaluated in section $4 \mathrm{~b}$. Section 5 summarizes the results. Energy and water budget equations derived in section 2 can be applied to an atmospheric column over ocean and land. However, because the surface latent heat flux product used in section 4 includes fluxes only for ocean surfaces, our focus, and the analysis of the enthalpy flux associated with water mass transfer, is limited to over the ocean. Because both turbulent fluxes and energy fluxes associated with mass transfer are all enthalpy fluxes, we refer to them collectively as the enthalpy flux. Therefore, we use surface sensible and latent heat fluxes, as they are generally used, to distinguish them from the enthalpy flux associated with water mass transfer in this paper.

\section{Atmospheric energy and water budget equations}

The energy budget equations presented below are similar to those used in earlier studies (e.g., Peixoto and Oort 1992; Trenberth 1997). Although column integrated atmospheric energy equations do not depend on the choice of the vertical coordinate system, revised equations are formulated in a dry-air mass coordinate. Revisions also include the formulation of energy storage per unit mass of dry air instead of moist air as it is the former that is strictly conserved. We treat dry air and water vapor as independent components of a mixture. Furthermore, we explicitly distinguish between liquid and ice cloud particles in our accounting of moisture storage and precipitation. Our derivation follows the derivation of moist convection equations formulated by Bannon (2002). However, an important difference is that we assume hydrostatic balance in our derivation as a reasonable assumption for the horizontal and temporal scales for which the equations are applied. We also assume that dry air, water vapor, and hydrometeors in the parcel are all at the same temperature. In addition, we ignore the volume occupied by hydrometeors.

Following Lauritzen et al. (2018), we use dry air mass per unit area $M_{a}$ above the height $z$ as the vertical coordinate

$$
\eta=M_{a}(x, y, z, t)=\int_{z}^{\infty} \rho_{a} d z,
$$

where $\rho$ is the density and the subscript $a$ indicates dry air. (See appendix A for a list of variables.) We do not normalize $M_{a}(x, y, z, t)$ by dividing by the mass of dry air above the surface, which is done in Lauritzen et al. (2018), so that $\eta$ at the surface changes spatially and temporally. As noted by Lauritzen et al. (2018), $M_{a}$ is not a directly measurable quantity. Also the sum of the column-integrated mass of dry air and water vapor multiplied by gravitational acceleration differs from surface moist air pressure because the sum of dry air and water vapor partial pressures is equal to the mass of the atmospheric column including hydrometeors (Lauritzen et al. 2018). We define the vertical velocity of dry air $\omega_{a}$ as

$$
\omega_{a} \equiv \frac{D M_{a}}{D t}
$$

where the material derivative is defined following a dry-air parcel as

$$
\frac{D}{D t} \equiv \frac{\partial}{\partial t}+\mathbf{U}_{a} \cdot \nabla_{\eta}+\omega_{a} \frac{\partial}{\partial \eta}
$$

and $\mathbf{U}_{a}$ is the horizontal velocity of dry air. We use the dry-air velocity as the reference velocity and set up equations following a 
parcel moving with the dry-air velocity. The mass continuity equation of dry air is

$$
\nabla_{\eta} \cdot \mathbf{U}_{a}+\frac{\partial \omega_{a}}{\partial \eta}=0
$$

where $\nabla_{\eta}$ is the horizontal gradient operator applied with dryair mass held constant.

We start with some definitions and set up equations that are used later in the derivation. A general form of local conservation of a property $\chi$ can be expressed as (e.g., Bohren and Albrecht 1998, chapter 7)

$$
\frac{\partial \chi}{\partial t}+\nabla_{\eta} \cdot\left(\chi \mathbf{U}_{\chi}\right)+\frac{\partial\left(\chi \omega_{\chi}\right)}{\partial \eta}=\dot{\chi}
$$

where $\mathbf{U}_{\chi}$ and $\omega_{\chi}$ are the horizontal and vertical velocity with which $\chi$ is being transported with the flux of $\chi \mathbf{U}_{\chi}$ and $\chi \omega_{\chi}$, and $\dot{\chi}$ is the rate at which $\chi$ is being generated in the volume. Equation (4) can be derived from Eq. (5) with $\chi=m_{a}$, where $m_{a}$ is the mass of dry air in the volume. We consider water vapor, liquid and ice particles, rain, and snow, which are indicated by the respectively subscripts $v, l, i, r$, and $s$. Rain is liquid form precipitation and snow is solid form precipitation in this work. Their velocity, especially the vertical velocity of precipitation, is different from $\mathbf{U}_{a}$ such that the horizontal velocity of $\mathbf{U}_{\chi}=\mathbf{U}_{a}+\mathbf{v}_{\chi}$ and vertical velocity $\omega_{\chi}=\omega_{a}+w_{\chi}$, where $\chi$ is one of $v, l, i, r$, or $s$, and $\mathbf{v}_{\chi}$ and $w_{\chi}$ are velocities of $\chi$ that deviate from the dry-air velocity. The velocity of water vapor is close to the velocity of dry air, that is, $\mathbf{v}_{v}=w_{v} \approx 0$ since its diffusion velocity is small compared to $\mathbf{U}_{a}$. The mixing ratio of water vapor and hydrometeors present within the parcel is $r_{\chi}=\rho_{\chi} / \rho_{a}$, where $\rho_{\chi}$ is the density of $\chi$ (e.g., water vapor or hydrometeor) within the parcel. The advantage of using $\mathbf{U}_{a}$ as the reference velocity is that the mass of dry air in the parcel is conserved.

When we use the continuity equation of dry air [Eq. (4)], the definition given by Eq. (3), and velocity of $\chi$, the conservation of $\chi$ following the parcel moving with dry-air velocity is expressed as (see appendix B for the derivation)

$$
\frac{D}{D t}\left(\frac{\chi}{\rho_{a}}\right)=\frac{\dot{\chi}}{\rho_{a}}-\frac{1}{\rho_{a}}\left[\nabla_{\eta} \cdot\left(\chi \mathbf{v}_{\chi}\right)+\frac{\partial\left(\chi w_{\chi}\right)}{\partial \eta}\right],
$$

which states that $\chi$ changes when it has a source in the parcel $\dot{\chi}$ or by convergence of the flux in either the lateral or vertical direction. The convergence of the flux appears because the velocity of $\chi$ differs from the velocity of the parcel that is moving with the dry-air velocity.

The density of the parcel $\rho$ is $\rho=\rho_{a}\left(1+r_{v}+r_{l}+r_{i}+r_{r}+r_{s}\right)$, where $\rho_{a}$ is the density of dry air. The continuity equation including water vapor and hydrometeors is derived using $\chi=\rho_{\chi}$ in Eq. (6)

$$
\frac{D}{D t}\left(\sum_{j=v, l, i, r, s} r_{j}\right)=\sum_{j=v, l, i, r, s}-\left[\nabla_{\eta} \cdot\left(r_{j} \mathbf{v}_{j}\right)+\frac{\partial\left(r_{j} w_{j}\right)}{\partial \eta}\right],
$$

where $\sum_{j=v, l, i, r, s} \dot{r}_{j}=0$ is used. The mass continuity equation including dry air, water vapor, and hydrometeors is therefore [e.g., Kasahara 1974, Eq. (3.18)]

$$
\frac{D}{D t} \ln \left(\frac{\rho}{\rho_{a}}\right)+\nabla_{\eta} \cdot \mathbf{U}_{a}+\frac{\partial \omega_{a}}{\partial \eta}=J_{r},
$$

where $\rho_{a}=\partial \eta / \partial z$ and

$$
J_{r}=\sum_{j=v, l, i, r, s}-\left[\nabla_{\eta} \cdot\left(r_{j} \mathbf{v}_{j}\right)+\frac{\partial\left(r_{j} w_{j}\right)}{\partial \eta}\right] .
$$

Following Kasahara (1974), we expand the material derivative of Eq. (8) as

$$
\frac{\partial}{\partial t}\left(\rho \frac{\partial z}{\partial \eta}\right)+\nabla_{\eta} \cdot\left(\mathbf{U}_{a} \rho \frac{\partial z}{\partial \eta}\right)+\frac{\partial}{\partial \eta}\left(\omega_{a} \rho \frac{\partial z}{\partial \eta}\right)=J_{r} \rho \frac{\partial z}{\partial \eta} .
$$

The hydrostatic equation is

$$
\frac{\partial \Phi}{\partial \eta}=-\frac{1}{\rho} \frac{\partial p}{\partial \eta}
$$

where geopotential $\Phi$ is $g z$. Equations (10) and (11) give

$$
\frac{\partial}{\partial \eta}\left(\frac{\partial p}{\partial t}\right)+\nabla_{\eta} \cdot\left(\mathbf{U}_{a} \frac{\partial p}{\partial \eta}\right)+\frac{\partial}{\partial \eta}\left(\omega_{a} \frac{\partial p}{\partial \eta}\right)=-g J_{r} \rho \frac{\partial z}{\partial \eta} .
$$

The mass continuity equations in the form of Eqs. (10) and (12) are used to derive the total energy equation later in this section.

The kinetic energy of a unit mass of dry air is (Starr 1945; Lauritzen et al. 2018)

$$
\frac{D k_{a}}{D t}=-\mathbf{U}_{a} \cdot \nabla_{\eta} \Phi-\frac{\mathbf{U}_{a}}{\rho_{a}} \cdot \nabla_{\eta} p-J_{\mathrm{fr}},
$$

where $p$ is the pressure and $J_{\mathrm{fr}}$ is the rate of work done by friction. The friction term includes the momentum transferred from hydrometeors. The derivation of Eq. (13) follows from section 8 of Starr (1945) with a hydrostatic assumption. The kinetic energy of water vapor and hydrometers within the parcel and the kinetic energy transported by convergence is obtained with Eq. (6) by setting $\chi=k_{\chi}$. When the resulting equation is added to Eq. (13), the kinetic energy equation for a unit mass of dry air containing water vapor and hydrometeors is

$$
\frac{D k}{D t}=-\mathbf{U}_{a} \cdot \nabla_{\eta} \Phi-\frac{\mathbf{U}_{a}}{\rho} \cdot \nabla_{\eta} p-J_{\mathrm{fr}}+J_{\mathrm{dif}, k}-J_{\text {fallout }, k},
$$

where $k$ is the kinetic energy per unit mass:

$$
k=k_{a}+r_{v} k_{v}+r_{l} k_{l}+r_{i} k_{i}+r_{r} k_{r}+r_{s} k_{s} .
$$

We separate source and convergence terms into two terms due to diffusion $J_{\mathrm{dif}, k}$ and fallout $J_{\text {fallout }, k}$. The $J_{\mathrm{dif}, k}$ term includes water vapor and liquid and ice particles, and $J_{\text {fallout }, k}$ includes rain and snow. These terms are

$$
J_{\mathrm{dif}, k}=\sum_{j=v, l, i} \dot{r}_{j} k_{j}-r_{j}\left[\nabla_{\eta} \cdot\left(k_{j} \mathbf{v}_{j}\right)+\frac{\partial\left(k_{j} w_{j}\right)}{\partial \eta}\right]
$$

and

$$
J_{\text {fallout }, k}=\sum_{j=r, s} \dot{r}_{j} k_{j}-r_{j}\left[\nabla_{\eta} \cdot\left(k_{j} \mathbf{v}_{j}\right)+\frac{\partial\left(k_{j} w_{j}\right)}{\partial \eta}\right],
$$

where $\dot{r}_{v}, \dot{r}_{l}, \dot{r}_{i}, \dot{r}_{r}$, and $\dot{r}_{s}$ are the time rate of change of water vapor, liquid and ice particles, rain, and snow mixing ratios due to 
condensation, evaporation, sublimation, fusion, and coagulation. The water mass is conserved so that $\dot{r}_{v}+\dot{r}_{l}+\dot{r}_{i}+\dot{r}_{r}+\dot{r}_{s}=0$.

The thermodynamic equation of moist air is (see appendix C for detail)

$$
\frac{D c_{p} T}{D t}-\alpha \frac{D p}{D t}=J_{\text {rad }}+J_{\text {dif }, T}+J_{\text {fallout }, T}+J_{\text {phase }}+J_{\text {trans }}+J_{\text {fr }},
$$

where the specific volume of the parcel $\alpha$ is defined by Eq. (C3) and the mass-weighted heat capacity $c_{p}$ is

$$
c_{p}=c_{p_{m}}+r_{l} c_{l}+r_{i} c_{i}+r_{r} c_{l}+r_{s} c_{i},
$$

where $c_{p m}$ is the specific heat capacity of moist air at constant pressure and $c_{l}$ and $c_{i}$ are, respectively, the specific heat capacity of liquid water and ice. The diabatic heating by radiation $J_{\text {rad }}$ is the sum of radiative heating caused by emission and absorption by water vapor (and other absorbing gases) and hydrometeors:

$$
J_{\mathrm{rad}}=J_{\mathrm{rad}_{m}}+J_{\mathrm{rad}_{l}}+J_{\mathrm{rad}_{i}}+J_{\mathrm{rad}_{r}}+J_{\mathrm{rad}_{s}} .
$$

Other energy flux terms are diffusion of the enthalpy caused by water vapor, liquid, and ice cloud particles

$$
\begin{aligned}
J_{\mathrm{dif}, T}= & \dot{r}_{v} c_{p_{v}} T-r_{v} \nabla_{\eta} \cdot\left(c_{p_{v}} T \mathbf{v}_{v}\right)-r_{v} \frac{\partial\left(c_{p_{v}} T w_{v}\right)}{\partial \eta} \\
& +\sum_{j=l, i}\left[\dot{r}_{j} c_{j} T-r_{j} \nabla_{\eta} \cdot\left(c_{j} T \mathbf{v}_{j}\right)-r_{j} \frac{\partial\left(c_{j} T w_{j}\right)}{\partial \eta}\right],
\end{aligned}
$$

transport of the enthalpy associated with rain and snow

$$
J_{\text {fallout }, T}=\sum_{j=r, s}\left[\dot{r}_{j} c_{j} T-r_{j} \nabla_{\eta} \cdot\left(c_{j} T \mathbf{v}_{j}\right)-r_{j} \frac{\partial\left(c_{j} T w_{j}\right)}{\partial \eta}\right],
$$

and enthalpy transport by conduction

$$
J_{\text {trans }}=\nabla_{\eta} \cdot\left(k_{T} \nabla_{\eta} T\right)+\frac{\partial}{\partial \eta}\left(k_{T} \frac{\partial T}{\partial \eta}\right) .
$$

The term $J_{\text {fr }}$ is the diabatic heating due to friction that appears in Eq. (14), and $k_{T}$ in Eq. (23) is thermal conductivity. The magnitude of $J_{\text {trans }}$ is only significant at the atmospheresurface boundary. Sensible heat flux appears at the surface boundary when the energy balance equation is integrated over the atmospheric column. The enthalpy of each constituent changes when the mixing ratio of each constituent changes. For example, cloud particles coagulate and form raindrops, which involves no enthalpy change because we assume that the temperature is the same for all hydrometeors. Diabatic heating due to water phase change within the parcel occurs through eight different paths: water vapor condenses to form liquid particles, raindrops, and deposits to form ice crystals or snowflakes at the rate of, respectively, $\dot{r}_{v l}, \dot{r}_{v r}, \dot{r}_{v i}$, and $\dot{r}_{v s}$. Liquid particles or raindrops freeze to form ice crystals or snowflakes at the rate of, respectively $\dot{r}_{l i}, \dot{r}_{r i}, \dot{r}_{l s}$ and $\dot{r}_{r s}$. The reverse process can occur. Therefore, a negative $\dot{r}_{v r}$ accounts for evaporation of raindrops. The net effect determining diabatic heating due to water phase change is

$$
J_{\text {phase }}=l_{v}\left(\dot{r}_{v l}+\dot{r}_{v r}\right)+l_{s}\left(\dot{r}_{v i}+\dot{r}_{v s}\right)+l_{f}\left(\dot{r}_{l i}+\dot{r}_{r i}+\dot{r}_{l s}+\dot{r}_{r s}\right),
$$

where $l_{v}, l_{s}$, and $l_{f}$ are, respectively, enthalpy of vaporization, sublimation, and fusion of water.

To express the derivative of the total energy of the parcel per unit mass, we use Eqs. (14) and (18), multiply them by $\rho \partial z / \partial \eta$, multiply the continuity Eq. (10) by $k$ or $c_{p} T$, and add resulting four equations to obtain

$$
\begin{aligned}
& \frac{\partial}{\partial t}\left[\left(c_{p} T+k\right) \rho \frac{\partial z}{\partial \eta}\right]+\nabla_{\eta} \cdot\left[\mathbf{U}_{a}\left(c_{p} T+k\right) \rho \frac{\partial z}{\partial \eta}\right]+\frac{\partial}{\partial \eta}\left[\omega_{a}\left(c_{p} T+k\right) \rho \frac{\partial z}{\partial \eta}\right] \\
& \quad=\frac{\partial z}{\partial \eta} \frac{\partial p}{\partial t}+\frac{\partial z}{\partial \eta} \omega_{a} \frac{\partial p}{\partial \eta}-\rho \frac{\partial z}{\partial \eta} \mathbf{U}_{a} \cdot \nabla_{\eta} \Phi+\rho \frac{\partial z}{\partial \eta}\left[J_{\text {rad }}+J_{\text {dif }, T}+J_{\text {fallout }, T}+J_{\text {phase }}+J_{\text {trans }}+J_{\text {dif }, k}+J_{\text {fallout }, k}+\left(c_{p} T+k\right) J_{r}\right]
\end{aligned}
$$

Using Eq. (11), the second term on the right side of Eq. (25) can be written as (Kasahara 1974)

$$
\frac{\partial z}{\partial \eta} \omega_{a} \frac{\partial p}{\partial \eta}=-\frac{\partial}{\partial \eta}\left(z \omega_{a} \rho \frac{\partial \Phi}{\partial \eta}\right)-z \frac{\partial}{\partial \eta}\left(\omega_{a} \frac{\partial p}{\partial \eta}\right)
$$

and the third term on the right side of Eq. (25) as

$$
-\rho \frac{\partial z}{\partial \eta} \mathbf{U}_{a} \cdot \nabla_{\eta} \Phi=-\nabla_{\eta} \cdot\left(\Phi \mathbf{U}_{a} \rho \frac{\partial z}{\partial \eta}\right)-z \nabla_{\eta} \cdot\left(\mathbf{U}_{a} \frac{\partial p}{\partial \eta}\right)
$$

Using Eq. (12), the sum of second terms on the right side of Eqs. (26) and (27) is

$$
-z \frac{\partial}{\partial \eta}\left(\omega_{a} \frac{\partial p}{\partial \eta}\right)-z \nabla_{\eta} \cdot\left(\mathbf{U}_{a} \frac{\partial p}{\partial \eta}\right)=z \frac{\partial}{\partial \eta}\left(\frac{\partial p}{\partial t}\right)+z g J_{r} \rho \frac{\partial z}{\partial \eta}
$$

Substituting Eqs. (26) and (27) and using Eq. (28) leads to the total energy equation of

$$
\begin{gathered}
\frac{\partial}{\partial t}\left[\left(c_{p} T+k\right) \rho \frac{\partial z}{\partial \eta}\right]+\nabla_{\eta} \cdot \mathbf{U}_{a}\left[\left(c_{p} T+k+\Phi\right) \rho \frac{\partial z}{\partial \eta}\right]+\frac{\partial}{\partial \eta}\left[\omega_{a}\left(c_{p} T+k+\Phi\right) \rho \frac{\partial z}{\partial \eta}\right] \\
=\frac{\partial}{\partial \eta}\left(z \frac{\partial p}{\partial t}\right)+\left(z g J_{r}+J_{\text {rad }}+J_{\text {dif }}+J_{\text {fallout }}+J_{\text {phase }}+J_{\text {trans }}\right) \rho \frac{\partial z}{\partial \eta},
\end{gathered}
$$


where

$$
\begin{aligned}
J_{\mathrm{dif}}= & J_{\mathrm{dif}, T}+J_{\mathrm{dif}, k}+\left(c_{p_{v}} T+k_{v}\right) J_{r_{v}}+\sum_{j=l, i}\left(c_{j} T+k_{j}\right) J_{r_{j}} \\
= & \sum_{j=v, l, i}\left\{\dot{r}_{j}\left(c_{j} T+k_{j}\right)-\nabla_{\eta} \cdot\left[r_{j}\left(c_{j} T+k_{j}\right) \mathbf{v}_{j}\right]\right. \\
& \left.-\frac{\partial\left[r_{j}\left(c_{j} T+k_{j}\right) w_{j}\right]}{\partial \eta}\right\},
\end{aligned}
$$

where $c_{v}=c_{p_{v}}$ and

$$
\begin{aligned}
J_{\text {fallout }}= & J_{\text {fallout }, T}+J_{\text {fallout }, k}+\sum_{j=r, s}\left(c_{j} T+k_{j}\right) J_{r_{j}} \\
= & \sum_{j=r, s}\left\{\dot{r}_{j}\left(c_{j} T+k_{j}\right)-\nabla_{\eta} \cdot\left[r_{j}\left(c_{j} T+k_{j}\right) \mathbf{v}_{j}\right]\right. \\
& \left.-\frac{\partial\left[r_{j}\left(c_{j} T+k_{j}\right) w_{j}\right]}{\partial \eta}\right\} .
\end{aligned}
$$

Equation (29) is equivalent to the total energy equation derived by Lauritzen et al. (2018) except that it includes advection terms due to water vapor and hydrometeors moving at different velocities from the dry-air velocity on the right side.

Equation (29) is integrated over the entire atmospheric column using the dry-air mass vertical coordinate

$$
\begin{aligned}
\int_{0}^{M_{a, \text { scc }}} & {\left[\frac{\partial\left(c_{p} T+k\right)}{\partial t}+\nabla_{\eta} \cdot \mathbf{U}_{a}\left(c_{p} T+k+\Phi\right)\right.} \\
& \left.+\frac{\partial \omega_{a}\left(c_{p} T+k+\Phi\right)}{\partial \eta}\right] \rho \frac{\partial z}{\partial \eta} d \eta \\
= & \int_{0}^{M_{a, \text { sfc }}} \int\left[\frac{\partial}{\partial \eta}\left(z \frac{\partial p}{\partial t}\right)+\left(z g J_{r}+J_{\text {rad }}+J_{\text {dif }}+J_{\text {fallout }}\right.\right. \\
& \left.\left.+J_{\text {phase }}+J_{\text {trans }}\right) \rho \frac{\partial z}{\partial \eta}\right] d \eta,
\end{aligned}
$$

where $M_{a \text {,sfc }}$ is the dry-air mass integrated over the column above the surface. With boundary conditions of $D M_{a} / D t=0$ at the top boundary and the boundary condition at the surface of

$$
\frac{\partial M_{a, \mathrm{sfc}}}{\partial t}+\mathbf{U}_{a} \cdot \nabla_{\eta} M_{a, \mathrm{sfc}}=\omega_{a}\left(M_{a, \mathrm{sfc}}\right)
$$

Eq. (32) becomes

$$
\begin{aligned}
\frac{1}{g} \frac{\partial}{\partial t} \int_{0}^{p_{\text {sfc }}}\left(c_{p} T+k\right) d p+\frac{1}{g} \nabla \cdot \int_{0}^{p_{\text {sfc }}} \mathbf{U}_{a}\left(c_{p} T+k+\Phi\right) d p \\
=z(0) \frac{\partial p(0)}{\partial t}-z\left(M_{a, \mathrm{sfc}}\right) \frac{\partial p\left(M_{a, \mathrm{sfc}}\right)}{\partial t}+\int_{M_{a, \mathrm{sfc}}}^{0}\left[\left(g z J_{r}+J_{\text {rad }}\right.\right. \\
\left.\left.\quad+J_{\text {dif }}+J_{\text {fallout }}+J_{\text {phase }}+J_{\text {trans }}\right) \rho \frac{\partial z}{\partial \eta}\right] d \eta
\end{aligned}
$$

where $z(0)$ is the height of the top boundary and $p(0)=0$, and $z\left(M_{a, \mathrm{sfc}}\right)$ and $p\left(M_{a, \mathrm{sfc}}\right)$ are, respectively, the surface height and pressure at the surface. The relationship $(\partial p / \partial t)_{M_{a, \text { sfc }}}=$ $\partial p\left(M_{a, \mathrm{scc}}\right) / \partial t+g(\rho \partial z / \partial \eta)_{M_{a, \mathrm{sfc}}}\left(\partial M_{a, \mathrm{sfc}} / \partial t\right)$ is used to derive Eq. (34). Equation (34) is equivalent to Eq. (5.11) of Kasahara (1974) except that the third term on the right side includes the advection of energy due to water vapor and hydrometeors moving at different velocities from the velocity of dry air. Because $z\left(M_{a, \mathrm{sfc}}\right)$ is constant with time, Eq. (34) can be written as

$$
\begin{aligned}
& \frac{1}{g} \frac{\partial}{\partial t} \int_{0}^{p_{\mathrm{sfc}}}\left(c_{p} T+k+\Phi_{s}\right) d p+\frac{1}{g} \nabla \cdot \int_{0}^{p_{\mathrm{sfc}}} \mathbf{U}_{a}\left(c_{p} T+k+\Phi\right) d p \\
& \quad=\int_{M_{a, \mathrm{sc}}}^{0}\left[\left(g z J_{r}+J_{\text {rad }}+J_{\text {dif }}+J_{\text {fallout }}+J_{\text {phase }}+J_{\text {trans }}\right) \rho \frac{\partial z}{\partial \eta}\right] d \eta,
\end{aligned}
$$

where $\Phi_{s}=g z\left(M_{a, \text { sfc }}\right)$. The first term in the integrand on the right side of Eq. (35) accounts for the advection of the mass of water vapor and hydrometeors. Integration of the two terms of the right side of Eq. (35) $J_{\text {rad }}$ and $J_{\text {phase }}$ can be expressed as

$$
\begin{aligned}
& \int_{M_{a, \mathrm{sfc}}}^{0}\left(J_{\mathrm{rad}}+J_{\text {phase }}\right) \rho \frac{\partial z}{\partial \eta} d \eta=\int_{0}^{\infty} \rho\left(J_{\text {rad }}+J_{\text {phase }}\right) d z \\
& =\left(R_{\mathrm{TOA}}-R_{\mathrm{sfc}}\right)+l_{v}\left(\dot{C}_{v l}+\dot{P}_{v r}\right)+l_{s}\left(\dot{C}_{v i}+\dot{P}_{v s}\right) \\
& \quad+l_{f}\left(\dot{C}_{l i}+\dot{P}_{r i}+\dot{P}_{l s}+\dot{P}_{r s}\right),
\end{aligned}
$$

where $R_{\mathrm{TOA}}$ and $R_{\mathrm{sfc}}$ are, respectively, the net TOA and surface irradiance, $\dot{P}_{j_{1} j_{2}}$ is the rate of column integrated precipitation of $j_{2}$ formed from $j_{1}$, and $\dot{C}_{j_{1} j_{2}}$ is the rate of column integrated net condensation, deposition, and freezing of $j_{2}$ formed from $j_{1}$. Integration of the $J_{\text {dif }}, J_{\text {fallout }}$, and $J_{\text {trans }}$ terms is

$$
\begin{aligned}
& \int_{M_{a, \mathrm{sfc}}}^{0}\left(J_{\text {trans }}+J_{\text {dif }}+J_{\text {fallout }}\right) \rho \frac{\partial z}{\partial \eta} d \eta \\
& =\frac{1}{g} \int_{0}^{p_{\text {sfc }}} \sum_{j=v, l, i, r, s} \dot{r}_{j} c_{j} T d p-\frac{1}{g} \int_{0}^{p_{\text {sfc }}} \sum_{j=v, l, i, r, s} \nabla \cdot r_{j} \mathbf{v}_{j}\left(k_{j}+c_{j} T\right) d p \\
& \quad+F_{\mathrm{SH}}+F_{v}+F_{\text {fallout }},
\end{aligned}
$$

where $\sum_{j=v, l, i, r, s} \dot{r}_{j} k_{j}=0, F_{\mathrm{SH}}$ is the sensible heat flux at the surface, $F_{v}$ is the enthalpy flux associated with water vapor from the surface $\left(F_{v}=\dot{E} c_{p_{v}} T\right), \dot{E}$ is the rate of evaporation from the surface, $F_{\text {fallout }}$ is the enthalpy flux through the atmosphere-surface boundary associated with precipitation ( $\left.F_{\text {fallout }}=-\dot{P}_{r} c_{r} T-\dot{P}_{s} c_{s} T\right)$, and $\dot{P}_{r}$, and $\dot{P}_{s}$ are, respectively, the rain and snow rate. Fluxes $F_{\mathrm{SH}}, F_{v}$, and $F_{\text {fallout }}$ are those at the lower boundary. We assume that $\mathbf{v}_{j}=0$ at the surface. In addition, mean kinetic energy carried by raindrops falling with $10 \mathrm{~m} \mathrm{~s}^{-1}$ at the monthly mean rain rate of $10 \mathrm{~mm}^{-1}{ }^{-1}$ (e.g., Adler et al. 2012) is approximately $0.1 \mathrm{~W} \mathrm{~m}^{-2}$. However, this is transitory and therefore extremely small on average. We subsequently ignore kinetic energy carried out by rain and snow. We also ignore horizontal enthalpy transport by conduction in $J_{\text {trans. }}$ 

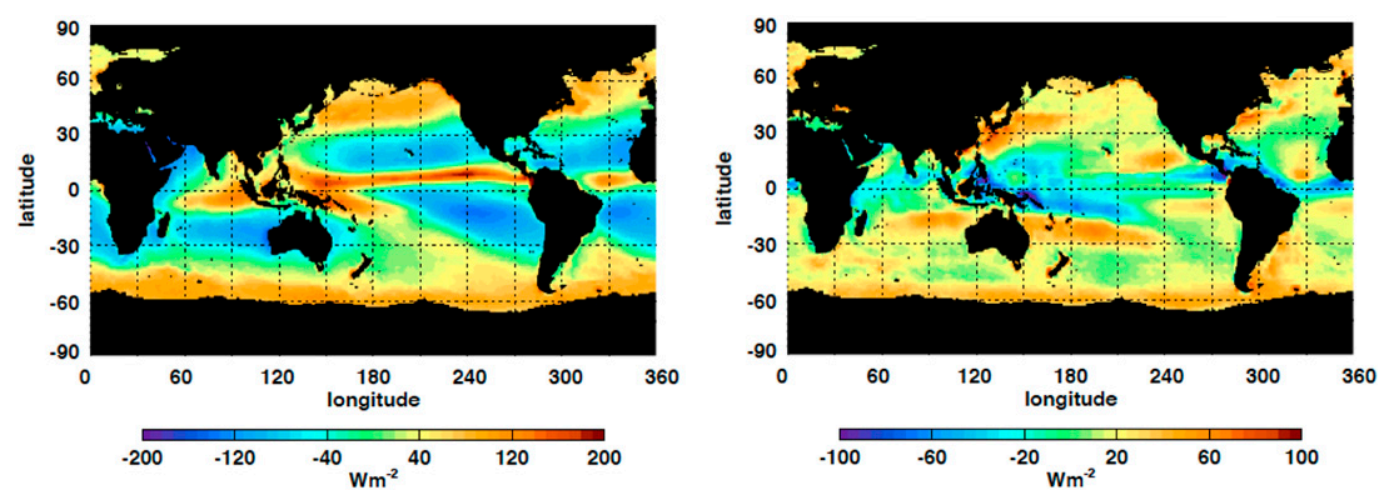

FIG. 1. (left) Precipitation rate multiplied by the enthalpy of vaporization minus latent heat flux $(\dot{P}-\dot{E})$ averaged over 16 years in $\mathrm{W} \mathrm{m}^{-2}$ computed with Global Precipitation Climatology Project (GPCP) and SeaFlux data products. (right) Difference of $\dot{P}-\dot{E}$ in $\mathrm{W} \mathrm{m}^{-2}$, i.e., the left plot minus $\dot{P}-\dot{E}$ derived from ERA-Interim.

Equation (35) is, therefore,

$$
\begin{aligned}
\frac{1}{g} \frac{\partial}{\partial t} \int_{0}^{p_{\mathrm{sfc}}}\left[c_{p} T+\Phi_{s}+k\right] d p+\frac{1}{g} \nabla \cdot \int_{0}^{p_{\mathrm{sfc}}} \mathbf{U}_{a}\left[c_{p} T+\Phi+k\right] d p \\
=\left(R_{\mathrm{TOA}}-R_{\mathrm{sfc}}\right)+l_{v}\left(\dot{C}_{v l}+\dot{P}_{v r}\right)+l_{s}\left(\dot{C}_{v i}+\dot{P}_{v s}\right)+l_{f}\left(\dot{C}_{l i}+\dot{P}_{r i}\right. \\
\left.+\dot{P}_{l s}+\dot{P}_{r s}\right)+F_{\mathrm{SH}}+F_{v}+F_{\text {fallout }}+\frac{1}{g_{j}} \sum_{j, l, i, r, s} \int_{0}^{p_{\mathrm{sfc}}} \dot{r}_{j} c_{j} T d p \\
\quad-\frac{1}{g} \int_{0}^{p_{\mathrm{sfc}}} \sum_{j=v, l, i, r, s} \nabla \cdot \mathbf{v}_{j} r_{j}\left(k_{j}+c_{j} T\right) d p-F_{\Phi},
\end{aligned}
$$

where

$$
F_{\Phi}=\frac{1}{g} \int_{0}^{p_{\mathrm{sfc}}} \sum_{j=v, l, i, r, s} \nabla \cdot \mathbf{v}_{j} r_{j} \Phi d p
$$

which is the potential energy flux due to changes of the vertical distribution of water mass in the column by their velocities deviating from dry-air velocity. Equation (38) is the energy balance equation of the atmospheric column. Equation (38) is similar to the energy balance equation of the atmospheric column derived in Trenberth and Fasullo [2018, their Eq. (17)] except diabatic heating due to net condensation of nonprecipitating hydrometeors is included, dry-air velocity is used for the reference velocity, and two enthalpy fluxes associated with water mass transfer $F_{v}$ and $F_{\text {fallout }}$ are explicitly expressed as two different terms (details are discussed in section 4a). In addition, Eq. (38) has extra terms on the right side because the mixing ratio of constituents within the column can change and hydrometeors can be advected with velocities different from the dry-air velocity.

The atmospheric energy budget equation that uses moist static energy and energy fluxes at boundaries is provided in appendix D [Eq. (D5)]. Two forms of atmospheric energy equations are used in section 3 to assess the effect of the transport of hydrometeors on the regional atmospheric energy budget.

\section{Evaluation of water mass balance and the effect of hydrometeor horizontal advection}

Equations (38) and (D5) include horizontal enthalpy fluxes associated with horizontal transport of hydrometeors. In the analysis by Kato et al. (2016), the horizontal transport of hydrometeors is neglected. In addition, all precipitation is assumed to be formed in the atmospheric column where fallout occurs. Furthermore, the water mass is not necessarily conserved when flux data products are integrated. We evaluate regional water mass balance and the impact of horizontal transport of hydrometers on regional energy budget in this section.

To assess the water mass balance in the atmospheric column with the data products used in the study by Kato et al. (2016), we compute regional precipitation rate $\dot{P}$ minus evaporation rate $\dot{E}$ in Fig. 1 . The precipitation rate is from version 2.3 of the Global Precipitation Climatology Project (GPCP; Adler et al. 2012) product multiplied by the enthalpy of vaporization at $0^{\circ} \mathrm{C}$. Temperature dependence of the enthalpy of vaporization is ignored here but is considered in section $4 \mathrm{~b}$. The evaporation rate is from the SeaFlux data product (Clayson and Bogdanoff 2013). We then compute the difference of $\dot{P}-\dot{E}$ from $\dot{P}-\dot{E}$ derived from ERA-Interim (Trenberth and Fasullo 2018). The difference provides an approximate estimate of regional water mass balance residuals when GPCP and SeaFlux are combined, although water mass is not conserved in ERA-Interim either. The terms $\dot{P}$ and $\dot{E}$ averaged over global ocean are, respectively, $87.0 \mathrm{~W} \mathrm{~m}^{-2}\left(3.0 \mathrm{~mm} \mathrm{day}^{-1}\right)$ and $85.4 \mathrm{~W} \mathrm{~m}^{-2}$. Figure 1 shows that regions with a larger negative difference extend from tropical western Pacific to south central Pacific. Regions with a positive difference are present at the south of the negative regions, as well as in midlatitude. Regions with a negative difference need a larger convergence of water in the atmosphere, a smaller $\dot{P}$ or a larger $\dot{E}$ to mitigate the regional water mass balance residual.

To illustrate the potential impact of the horizontal transport of hydrometeors (e.g., ice crystals) on the energy budget of an atmospheric column and to assess whether the transport 


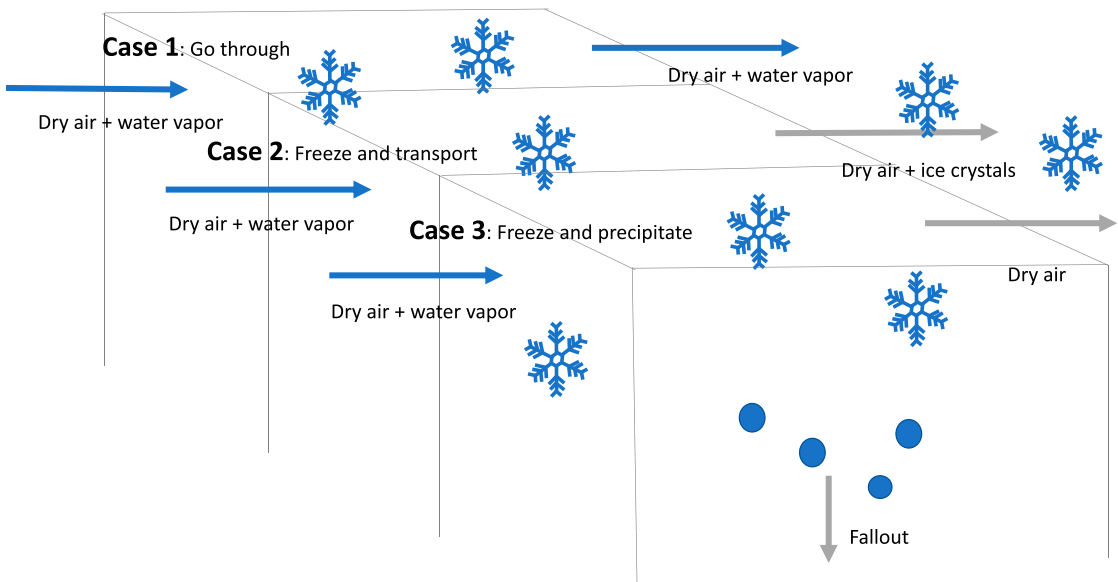

FIG. 2. Three cases to evaluate the effect of hydrometeor horizontal transport to the regional atmospheric energy budget. In each case water vapor is transported into the atmospheric column in which ice crystals are present. In case 1 , all water vapor is transported out of the column. Ice crystals are formed in cases 2 and 3 . In case 2, all ice crystals are transported out of the column while in case 3 the ice crystals precipitate and fall out.

explains a part of the regional energy budget residual, we consider three extreme cases shown schematically in Fig. 2. In each case water vapor is transported into the atmospheric column in which ice crystals are present. In case 1 , all water vapor is transported out of the column. In cases 2 and 3, all water vapor is condensed, freezes, and ice crystals are formed. In case 2, all ice crystals are transported out of the column while in case 3 the ice crystals melt and fallout. The reverse process of case 2 can occur somewhere else. All three cases are in a steady state. Table 1 summarizes the dry static energy, moist static energy and diabatic heating for these three cases using Eqs. (38) and (D5). Vertical integration and kinetic energy are omitted in the expression shown in Table 1.
Differences in diabatic heating rate, dry static energy convergence, moist static energy convergence, and $F_{\text {fallout }}$ between these cases are summarized in Table 2.

The largest difference of diabatic heating rate $l_{s} \dot{C}_{v i}$ occurs between case 2 and case 1 (Table 2), which is equivalent to the difference of column integrated dry and moist static energy convergence differences. Regional differences of dry and moist static energy divergences in the tropics can be larger than $100 \mathrm{~W} \mathrm{~m}^{-2}$. Even though this is an unrealistic and extreme case in which all water vapor is condensed and freezes to form ice crystals to be transported, it demonstrates that the horizontal transport of hydrometeors is to increase energy in the atmospheric column from which ice crystals are exported.

TABLE 1. Dry and moist static energy advection and diabatic heating associated with hydrometeor transport. Asterisks $(*)$ indicate that vertical integration and kinetic energy are omitted in the expression.

\begin{tabular}{|c|c|c|c|}
\hline & Case 1: Go through & Case 2: Freeze and transport & $\begin{array}{l}\text { Case 3: Freeze, melt, and } \\
\text { precipitate }\end{array}$ \\
\hline $\begin{array}{l}\text { Incoming dry static } \\
\text { energy* }\end{array}$ & $\mathbf{U}_{a}\left[\left(c_{p_{a}}+r_{v} c_{p_{v}}\right) T+\Phi\right]+r_{v} c_{v} T \mathbf{v}_{v}$ & $\mathbf{U}_{a}\left[\left(c_{p_{a}}+r_{v} c_{p_{v}}\right) T+\Phi\right]+r_{v} c_{p_{v}} T \mathbf{v}_{v}$ & $\mathbf{U}_{a}\left[\left(c_{p_{a}}+r_{v} c_{p_{v}}\right) T+\Phi\right]+r_{v} c_{v} T \mathbf{v}_{v}$ \\
\hline $\begin{array}{l}\text { Diabatic heating due to } \\
\text { freezing }\end{array}$ & 0 & $l_{s} \dot{C}_{v i}$ & $l_{s} \dot{C}_{v i}$ \\
\hline $\begin{array}{l}\text { Diabatic heating due to } \\
\text { fusion (precipitation) }\end{array}$ & 0 & 0 & $-l_{f} \dot{P}_{r i}$ \\
\hline $\begin{array}{l}\text { Outgoing dry static } \\
\text { energy* }\end{array}$ & $\mathbf{U}_{a}\left[\left(c_{p_{a}}+r_{v} c_{p_{v}}\right) T+\Phi\right]+r_{v} c_{v} T \mathbf{v}_{v}$ & $\mathbf{U}_{a}\left[\left(c_{p_{a}}+r_{i} c_{i}\right) T+\Phi\right]+r_{i} c_{i} T \mathbf{v}_{i}$ & $\mathbf{U}_{a}\left(c_{p_{a}} T+\Phi\right)$ \\
\hline $\begin{array}{l}\text { Convergence of dry } \\
\text { static energy* }\end{array}$ & 0 & $\mathbf{U}_{a}\left(r_{v} c_{p_{v}}-r_{i} c_{i}\right) T+r_{v} \mathbf{v}_{v} T\left(c_{p_{v}}-c_{i}\right)$ & $r_{v} c_{p_{v}} T\left(\mathbf{U}_{a}+\mathbf{v}_{v}\right)$ \\
\hline $\begin{array}{l}\text { Incoming moist static } \\
\text { energy* }\end{array}$ & $\begin{array}{c}\mathbf{U}_{a}\left[\left(c_{p_{a}}+r_{v} c_{p_{v}}\right)\right. \\
\left.T+\Phi+l_{v} r_{v}\right]+r_{u}\left(c_{u} T+l_{\nu}\right) \mathbf{v}_{u}\end{array}$ & $\begin{array}{c}\mathbf{U}_{a}\left[\left(c_{p_{a}}+r_{v} c_{p_{v}}\right)\right. \\
\left.T+\Phi+l_{v} r_{\nu}\right]+r_{u}\left(c_{\nu} T+l_{\nu}\right) \mathbf{v}_{u}\end{array}$ & $\begin{array}{c}\mathbf{U}_{a}\left[\left(c_{p_{a}}+r_{v} c_{p_{v}}\right)\right. \\
\left.T+\Phi+l_{u} r_{u}\right]+r_{u}\left(c_{u} T+l_{u}\right) \mathbf{v}_{u}\end{array}$ \\
\hline $\begin{array}{l}\text { Outgoing moist } \\
\text { static energy* }\end{array}$ & $\begin{array}{c}\mathbf{U}_{a}\left[\left(c_{p_{a}}+r_{v} c_{p_{v}}\right)\right. \\
\left.T+\Phi+l_{v} r_{v}\right]+r_{v}\left(c_{v} T+l_{v}\right) \mathbf{v}_{v}\end{array}$ & $\begin{array}{c}\mathbf{U}_{a}\left[\left(c_{p_{a}}+r_{i} c_{i}\right)\right. \\
\left.T+\Phi-l_{f} r_{i}\right]+r_{i}\left(c_{i} T-l_{f}\right) \mathbf{v}_{i}\end{array}$ & $\mathbf{U}_{a} c_{p_{a}} T+\Phi$ \\
\hline $\begin{array}{l}\text { Convergence of moist } \\
\text { static energy* }\end{array}$ & 0 & $\begin{array}{c}\mathbf{U}_{a}\left[\left(r_{v} c_{p_{v}}-r_{i} c_{i}\right) T+\right. \\
\left.\left(r_{v} l_{v}+r_{i} l_{f}\right)\right]+r_{v} \mathbf{v}_{v} \\
{\left[\left(c_{p_{v}} T+l_{v}\right)-\left(c_{i} T-l_{f}\right)\right]}\end{array}$ & $r_{v}\left(c_{p_{v}} T+l_{v}\right)\left(\mathbf{U}_{a}+\mathbf{v}_{v}\right)$ \\
\hline$F_{\text {fallout }}$ & 0 & 0 & $-c_{r} \dot{P}_{r} T$ \\
\hline
\end{tabular}


TABLE 2. Difference of diabatic heating and dry and moist static energies.

\begin{tabular}{lccc}
\hline \hline \multicolumn{1}{c}{ Energy difference } & Case $2^{\mathrm{a}}-$ Case 1 & Case $2^{\mathrm{a}}-$ Case 3 & Case 3 - Case 1 \\
\hline Diabatic heating difference & $l_{s} \dot{C}_{v i}$ & $-l_{f} \dot{P}_{r i}$ & $l_{s} \dot{C}_{v i}-l_{f} \dot{P}_{r i}$ \\
$\begin{array}{l}\text { Dry static energy convergence } \\
\text { difference }\end{array}$ & $\mathbf{U}_{a}\left(r_{v} c_{p_{v}}-r_{i} c_{i}\right) T+r_{v} \mathbf{v}_{v} T\left(c_{p_{v}}-c_{i}\right)$ & $-r_{i} c_{i} T\left(\mathbf{U}_{a}+\mathbf{v}_{i}\right)$ & $r_{v} c_{p_{v}} T\left(\mathbf{U}_{a}+\mathbf{v}_{v}\right)$ \\
$\begin{array}{l}\text { Moist static energy convergence } \\
\text { difference }\end{array}$ & $\mathbf{U}_{a}\left[\left(r_{v} c_{p_{v}}-r_{i} c_{i}\right)\right.$ & $r_{i}\left(-c_{i} T+l_{f}\right)\left(\mathbf{U}_{a}+\mathbf{v}_{i}\right)$ & $r_{v}\left(c_{p_{v}} T+l_{v}\right)\left(\mathbf{U}_{a}+\mathbf{v}_{v}\right)$ \\
$F_{\text {fallout }}$ & $\left.T+r_{v} l_{s}\right]+r_{v} \mathbf{v}_{v}\left[\left(c_{p_{v}}-c_{i}\right) T+l_{s}\right]$ & $c_{r} \dot{P}_{r} T$ & $-c_{r} \dot{P}_{r} T$ \\
\hline
\end{tabular}

${ }^{\mathrm{a}}$ For a steady state $r_{v} \mathbf{v}_{v}=r_{i} \mathbf{v}_{i}$.

In summary, a part of regional energy balance residual shown in Kato et al. (2016) is due to regional water mass imbalance. If a larger water vapor convergence that is needed to reduce the water mass balance residual over tropical western pacific and the additional convergence is associated with diabatic heating by condensation or freezing (e.g., a combination of cases 2 and 3), then the additional water vapor convergence also is to increase diabatic heating in the atmospheric column. Considering this process that is missing in Kato et al. (2016), therefore, can reduce regional water mass and energy balance residuals. The horizontal transport of hydrometeors, however, only affects regional energy budget and does not contribute to the global energy budget residual.

\section{Enthalpy fluxes associated with data products integration}

There are energy fluxes that are not included in an individual data product but arise when multiple energy flux data products are integrated. The terms $F_{v}$ and $F_{\text {fallout in Eqs. (38) and (D5) }}$ are generally not included in turbulence flux data products. We estimate these fluxes in section $4 \mathrm{a}$. In addition, computing diabatic heating terms in Eq. (38) requires the knowledge of the phase and temperature of hydrometeors (e.g., height where condensation occurs) (e.g., Shige et al. 2004; Tao et al. 2006; Nelson et al. 2016). In section 4b, we investigate the effect of temperature dependence of the enthalpy of vaporization to diabatic heating estimates.

\section{a. Energy transfer associated with mass transfer}

Equations (38) and (D5) contain the horizontal enthalpy flux and enthalpy flux associated with precipitation $F_{\text {fallout }}$ and evaporation $F_{v}$. As pointed out by Mayer et al. (2017), the reference temperature needs to be defined to compute enthalpy fluxes. Mayer et al. (2017) and Trenberth and Fasullo (2018) use $0^{\circ} \mathrm{C}$ as a reference temperature. However, when the mass-weighted global mean ocean or atmosphere temperature is used as the reference temperature, the flux divided by the heat capacity of ocean or atmosphere is the temperature change (appendix E). In this section, we estimate $F_{\text {fallout }}$ and $F_{v}$ using mass-weighted ocean and atmosphere temperature as the reference temperature. As pointed out by Mayer et al. (2017), however, the same reference temperature for the atmosphere and ocean is required when the energy budget of the atmosphere and ocean combined system is considered. Moving water between the atmosphere and ocean should not alter the energy budget of the ocean and atmosphere combined system. For practical purposes, therefore, the use of $0^{\circ} \mathrm{C}$ as a reference temperature for both ocean and atmosphere in computing the enthalpy flux associated with water mass transfer is a reasonable compromise (Mayer et al. 2017; Trenberth and Fasullo 2018).

While not significantly different from $0^{\circ} \mathrm{C}$, the global mean mass-weighted ocean mean temperature is $3.7^{\circ} \mathrm{C}$. This value is from the World Ocean Atlas (WOA) 2013 V2 ocean atlas climatology product (Locarnini et al. 2013) and includes the entire ocean depth. In the ocean mean temperature estimate, the mass is assumed to be independent of depth and salinity dependence is ignored (i.e., the mass-weighted mean is therefore equal to the volume weighted mean). To derive the massweighted global mean temperature of the atmosphere we use tropical and midlatitude summer standard atmospheres. For both atmospheres, the mass-weighted mean temperature is close to $450-\mathrm{hPa}$ air temperature. Therefore, we use the global mean $450-\mathrm{hPa}$ air temperature of $255 \mathrm{~K}$ for $\bar{T}_{\mathrm{atm}}$ in the following computations.

We compute enthalpy transported from the atmosphere to the ocean by precipitation using

$$
F_{\text {fallout }, \text { ocn }} \equiv c_{w} \dot{P}\left(T_{w}-\bar{T}_{\text {ocn }}\right),
$$

where $\bar{T}_{\text {ocn }}$ is the mass-weighted ocean global mean temperature, $c_{w}$ is either the specific heat capacity of liquid water $c_{l}$ or ice $c_{i}$, and $T_{w}$ is the wet-bulb temperature. Because the temperature of a raindrop is close to the wet-bulb temperature near the surface (Gosnell et al. 1995; Fairall et al. 1996), we use the sea level ( $2 \mathrm{~m}$ ) wet-bulb temperature for $T_{w}$ in this study. While enthalpy is transported to the ocean by precipitation at the rate of $c_{w} \dot{P}\left(T_{w}-\bar{T}_{\text {ocn }}\right)$, enthalpy is also extracted from the atmosphere at the rate of

$$
F_{\text {fallout,atm }} \equiv-c_{w} \dot{P}\left(T_{w}-\bar{T}_{\text {atm }}\right)
$$

where $\bar{T}_{\text {atm }}$ is the mass-weighted global mean temperature of the atmosphere. The apparent flux difference expressed by Eqs. (40) and (41) arises because the enthalpy flux is computed based on how the transport of $c_{w} \dot{P} T_{w}$ affects the mass-weighted global mean ocean or atmosphere temperature, although the enthalpy transported by precipitation $c_{w} \dot{P} T_{w}$ is conserved.

In addition to the enthalpy flux associated with precipitation, enthalpy flux is also associated with mass transfer by water 

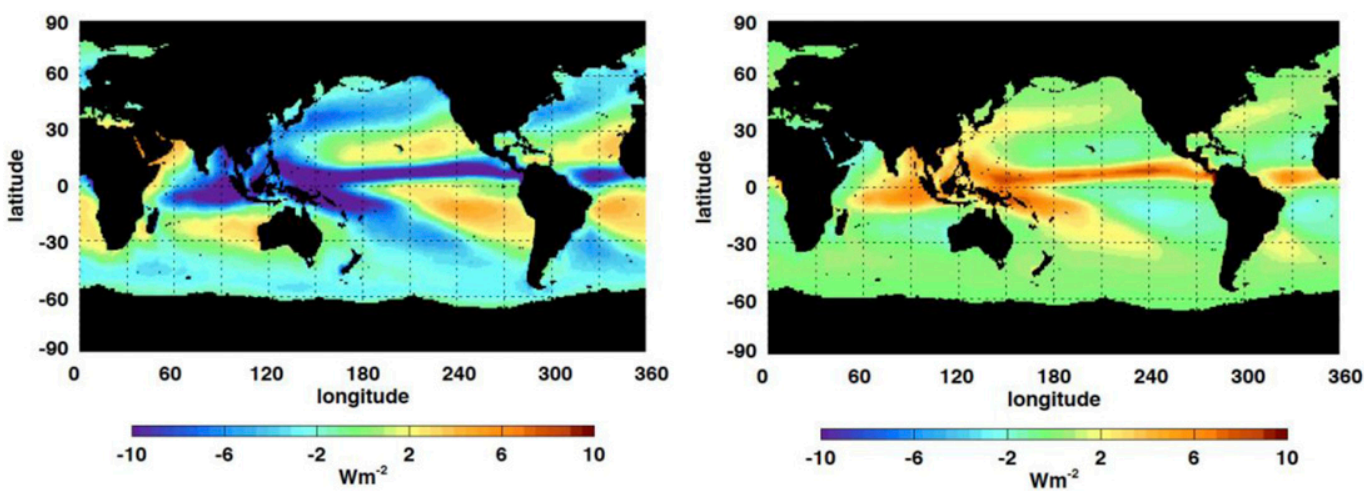

FIG. 3. Climatological mean of the net effect of enthalpy flux associated with water mass transfer (i.e., precipitation and evaporation) (left) to the atmosphere, $F_{v \text {,atm }}-F_{\text {fallout,atm }}$, and (right) to ocean, $F_{\text {fallout,ocn }}-F_{v \text {,ocn }}$, in W m ${ }^{-2}$, where $F_{\text {fallout,ocn }}, F_{\text {fallout,atm }}, F_{v \text {,ocn }}$, and $F_{v \text {,atm }}$ are defined, respectively, by Eqs. (40)-(43). The reference temperature of the atmosphere is $255 \mathrm{~K}$ and the reference temperature for ocean is $277 \mathrm{~K}$. Sixteen years of data from March 2000 through February 2016 are used.

vapor evaporated from the ocean surface. Similar to flux by precipitation, enthalpy flux from the ocean and to the atmosphere caused by evaporation is, respectively,

$$
F_{v, \text { ocn }} \equiv-c_{p_{v}} \dot{E}\left(T_{\text {skin }}-\bar{T}_{\text {ocn }}\right)
$$

and

$$
F_{v, \mathrm{~atm}} \equiv c_{p_{v}} \dot{E}\left(T_{\mathrm{skin}}-\bar{T}_{\mathrm{atm}}\right)
$$

where $c_{p_{v}}$ is the specific heat capacity of water vapor at constant pressure, $T_{\text {skin }}$ is the surface skin temperature, and $\dot{E}$ is the evaporation rate. Equation (42) uses $c_{p_{v}}$, which differs from Eq. (5) of Mayer et al. (2017), which uses specific heat capacity of liquid water.

To understand the spatial distribution of the enthalpy fluxes, Fig. 3 shows $-c_{w} \dot{P}\left(T_{w}-\bar{T}_{\text {atm }}\right)+c_{p_{v}} \dot{E}\left(T_{\text {skin }}-\bar{T}_{\text {atm }}\right)$ on the left and $c_{w} \dot{P}\left(T_{w}-\bar{T}_{\text {ocn }}\right)-c_{p_{v}} \dot{E}\left(T_{\text {skin }}-\bar{T}_{\text {ocn }}\right)$ on the right. We use 2-m air temperature and humidity from the Goddard Earth Observing System Model (GEOS)-5.4.1 reanalysis product (Rienecker et al. 2008) to compute monthly mean wet-bulb temperature. In addition, the GEOS-5.4.1 reanalysis product provides monthly mean surface skin temperatures. We use version 2.3 Global Precipitation Climatology Project (GPCP; Adler et al. 2012) data product for monthly mean precipitation and the SeaFlux product (Clayson and Bogdanoff 2013) for monthly mean evaporation rate. The left plot is, therefore, the net enthalpy transported to the atmosphere and the right plot is the net enthalpy transported to the ocean. We assume that precipitation is in liquid phase when $T_{w}>273.2 \mathrm{~K}$ and in solid phase when $T_{w} \leq 273.2 \mathrm{~K}$. Hence, the specific heat capacity of liquid or ice is used for $c_{w}$, depending on $T_{w}$. Once $-c_{w} \dot{P}\left(T_{w}-\bar{T}_{\text {atm }}\right)+c_{p_{v}} \dot{E}\left(T_{\text {skin }}-\bar{T}_{\text {atm }}\right)$ is averaged over the global ocean for 16 years (January 2001 to December 2016), the mean flux is $-2.3 \mathrm{~W} \mathrm{~m}^{-2}$. The average of $c_{w} \dot{P}\left(T_{w}-\bar{T}_{\text {ocn }}\right)-c_{p_{v}} \dot{E}\left(T_{\text {skin }}-\bar{T}_{\text {ocn }}\right)$ over the global ocean is $0.7 \mathrm{~W} \mathrm{~m}^{-2}$. Therefore, the effect of the enthalpy flux associated with water mass transfer is to cool the atmosphere and warm the ocean. When $0^{\circ} \mathrm{C}$ is used for both reference temperatures $\bar{T}_{\text {ocn }}$ and $\bar{T}_{\text {atm }},-c_{w} \dot{P}\left(T_{w}-\bar{T}_{\text {atm }}\right)+c_{p_{v}} \dot{E}\left(T_{\text {skin }}-\bar{T}_{\text {atm }}\right)$ averaged over the global ocean is $-1.0 \mathrm{~W} \mathrm{~m}^{-2}$ and $c_{w} \dot{P}\left(T_{w}-\bar{T}_{\text {ocn }}\right)-c_{p_{v}} \dot{E}\left(T_{\text {skin }}-\bar{T}_{\text {ocn }}\right)$ averaged over the global ocean is $1.0 \mathrm{~W} \mathrm{~m}^{-2}$. The effect of enthalpy transport associated with water mass transfer to the column of ocean and atmosphere combined is the sum of $-c_{w} \dot{P} T_{w}+c_{p_{v}} \dot{E} T_{\text {skin }}$ and $c_{w} \dot{P} T_{w}-c_{p_{v}} \dot{E} T_{\text {skin }}$. Therefore, there is no net effect to the atmosphere and ocean columns combined, which is also achieved using the same reference temperature for the atmosphere and ocean (i.e., $\bar{T}_{\text {atm }}=\bar{T}_{\text {ocn }}$ ).

\section{b. Diabatic heating rate in the atmosphere by precipitation}

As indicated by Eq. (38), the phase of hydrometeors is needed to compute diabatic heating rate due to precipitation. In addition, the temperature at which precipitation is formed is different from a 2-m wet-bulb temperature, our assumed hydrometeor temperature in section $3 \mathrm{a}$, when it falls to the ground. Therefore, the enthalpy transferred to or from hydrometeors to make their temperature a 2-m wetbulb temperature after they form needs to be considered. Because a 2-m wet-bulb temperature is generally higher than a temperature at which precipitation is formed, the diabatic heating rate due to precipitation is expected to be smaller when the enthalpy transport to the hydrometeors is included.

To estimate diabatic heating rate by precipitation including the enthalpy transfer to make hydrometeors temperature a 2-m wet-bulb temperature, we again use the GPCP precipitation data product. Because where and in which phase precipitating hydrometeors are formed are unknown from the data product, we assume that clouds and precipitation are formed in the same $1^{\circ} \times 1^{\circ}$ atmospheric column where precipitations occur. We use the enthalpy of vaporization (sublimation) when monthly regional $750-\mathrm{hPa}$ temperature is equal or greater (less) than $-10^{\circ} \mathrm{C}$ [i.e., $l_{v} \dot{P}_{v r}$ and $l_{s} \dot{P}_{v s}$ in Eq. (36)]. A study by $\mathrm{Hu}$ et al. (2010) shows that cloud particles detected by CALIPSO are almost all in liquid phase when midcloud temperature is 

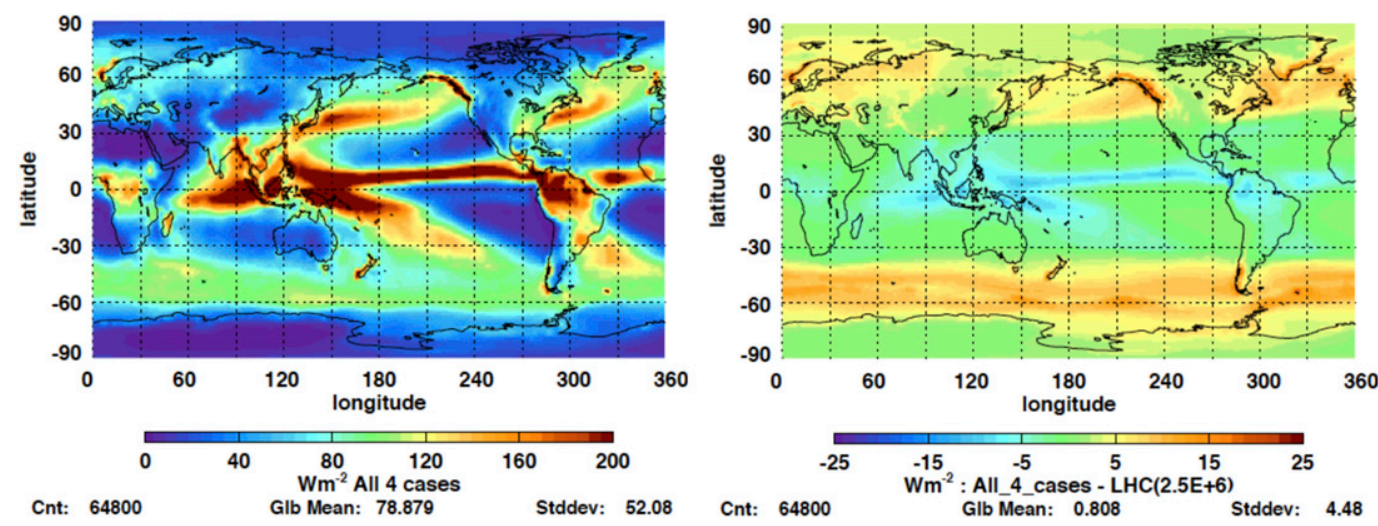

FIG. 4. (left) Annual mean precipitation averaged over 16 years from March 2000 through February 2016 from the Global Precipitation Climatology Project data product (Adler et al. 2012) version 2.3. Rain rate in mm day ${ }^{-1}$ is converted to diabatic heating in $\mathrm{W} \mathrm{m}^{-2}$ using the method explained in appendix F. (right) The difference of diabatic heating in the atmosphere due to precipitation shown on the left from the diabatic heating computed using the enthalpy of vaporization at $0^{\circ} \mathrm{C}$ (i.e., $2.5 \times 10^{6} \mathrm{~J} \mathrm{~kg}^{-1}$ ) in $\mathrm{W} \mathrm{m}^{-2}$.

higher than $-10^{\circ} \mathrm{C}$. The temperature dependence of the enthalpy of vaporization is computed by (Bohren and Albrecht 1998, p. 197)

$$
l_{v}=\left(c_{p_{v}}-c_{l}\right)\left(T_{750}-T_{0}\right)+l_{v 0},
$$

where $T_{750}$ is the $750-\mathrm{hPa}$ temperature, $T_{0}=0{ }^{\circ} \mathrm{C}, c_{p_{v}}$ is the specific heat capacity of water vapor at constant pressure at $0^{\circ} \mathrm{C}, c_{l}$ is the specific heat capacity of liquid water at $0^{\circ} \mathrm{C}$, and $l_{v 0}$ is the enthalpy of vaporization at $0^{\circ} \mathrm{C}$. The enthalpy of sublimation is nearly constant with temperature; it only changes less than $0.2 \%$ when the temperature is increased from $-40^{\circ}$ to $0^{\circ} \mathrm{C}$ (List 1949). Therefore, we use a constant enthalpy of sublimation at $0^{\circ} \mathrm{C}$. We also assume that the phase of precipitating hydrometeors depends on the 2-m wet-bulb temperature. This results in four different precipitation types depending on the $750-\mathrm{hPa}$ and 2-m wet-bulb temperatures (appendix F): warm rain (Precip. 1), freezing rain or sleet (Precip. 2), cold rain (Precip. 3), and snow (Precip. 4). The enthalpy transferred to change the temperature and phase of precipitating hydrometeors is included in converting the precipitation rate to diabatic heating rate for these four cases.

When warm rain forms at the $750-\mathrm{hPa}$ level and falls toward a surface with the $2-\mathrm{m}$ wet-bulb temperature, the enthalpy loss by the atmosphere to warm liquid water from $T_{750}$ to $T_{\text {skin }}$ is $c_{l}\left(T_{\text {skin }}-T_{750}\right)$, where $c_{l}\left(T_{w}-T_{750}\right)$ is transferred in the atmosphere and $c_{l}\left(T_{\text {skin }}-T_{w}\right)$ at the surface. When water vapor evaporates at the surface in the same column, and condenses at the $750-\mathrm{hPa}$ level, the enthalpy transferred to the atmosphere to cool water vapor from $T_{\text {skin }}$ to $T_{750}$ is $c_{p_{v}}\left(T_{\text {skin }}-T_{750}\right)$ per unit mass of water. The sum of the loss by the atmosphere is $c_{l}\left(T_{\text {skin }}-T_{750}\right)-c_{p_{v}}\left(T_{\text {skin }}-T_{750}\right)$. However, the loss is balanced by a larger diabatic heating rate by precipitation in the atmosphere $\left[\left(c_{p_{v}}-c_{l}\right)\left(T_{750}-T_{0}\right)+l_{v 0}\right]$ than the diabatic cooling rate at the surface by evaporation because of a lower temperature at which condensation occurs than the skin temperature at which evaporation takes place
$\left[\left(c_{p_{v}}-c_{l}\right)\left(T_{\text {skin }}-T_{0}\right)+l_{v 0}\right]$. Therefore, in this simple closed system scenario with precipitation and evaporation occurring in the same column, there is no net effect of temperature dependence of the enthalpy of vaporization in computing diabatic heating by precipitating hydrometeors to the combined ocean and atmosphere column.

Figure 4 (left) shows regional diabatic heating rates due to precipitation including the enthalpy transport to hydrometeors discussed above. Four different types of precipitation explained in appendix $\mathrm{F}$ are considered. The global annual mean diabatic heating rate by precipitation is $78.9 \mathrm{~W} \mathrm{~m}^{-2}$ with the $750-\mathrm{hPa}$ threshold temperature to determine the phase equal to $-10^{\circ} \mathrm{C}$, which is $0.8 \mathrm{~W} \mathrm{~m}^{-2}$ larger than the value computed with a constant enthalpy of vaporization at $0^{\circ} \mathrm{C}$ (i.e., $2.5 \times 10^{-6} \mathrm{~J} \mathrm{~kg}^{-1}$ ). The regional annual mean difference can be larger than $15 \mathrm{~W} \mathrm{~m}^{-2}$ as shown in the right plot of Fig. 4 (right). When the 750 -hPa threshold temperature is changed to $-5^{\circ} \mathrm{C}\left(-25^{\circ} \mathrm{C}\right)$, the global annual mean enthalpy release by precipitation is $79.7 \mathrm{~W} \mathrm{~m}^{-2}\left(78.1 \mathrm{~W} \mathrm{~m}^{-2}\right)$. The differences in the global annual mean are within $\pm 1 \mathrm{~W} \mathrm{~m}^{-2}$. However, GPCP precipitation rate might not include some snow precipitation, which can be up to $4 \mathrm{~W} \mathrm{~m}^{-2}$ (Stephens et al. 2012).

Even though we separated diabatic heating computations in four cases, the diabatic heating rate in the atmosphere largely depends on the water phase of hydrometers that fall on the surface. As a consequence, for a given rain rate, diabatic heating for Precip. 2 and 4 is larger than diabatic heating for Precip. 1 and 3. For Precip. 2 and 4, when snow melts at the surface ocean (or land) at the expense of the enthalpy from the ocean, diabatic cooling occurs at the surface. Figure 5 shows diabatic cooling due to melting snow at the surface. The global annual mean net effect is $-0.7 \mathrm{~W} \mathrm{~m}^{-2}$. Therefore, depending on the frequency of snow occurrence, when it is averaged over the globe and a year, snow warms the atmosphere (Fig. 4 right) and cools the surface (Fig. 5) up to $\sim 1 \mathrm{~W} \mathrm{~m}^{-2}$ compared to diabatic heating by rain. 


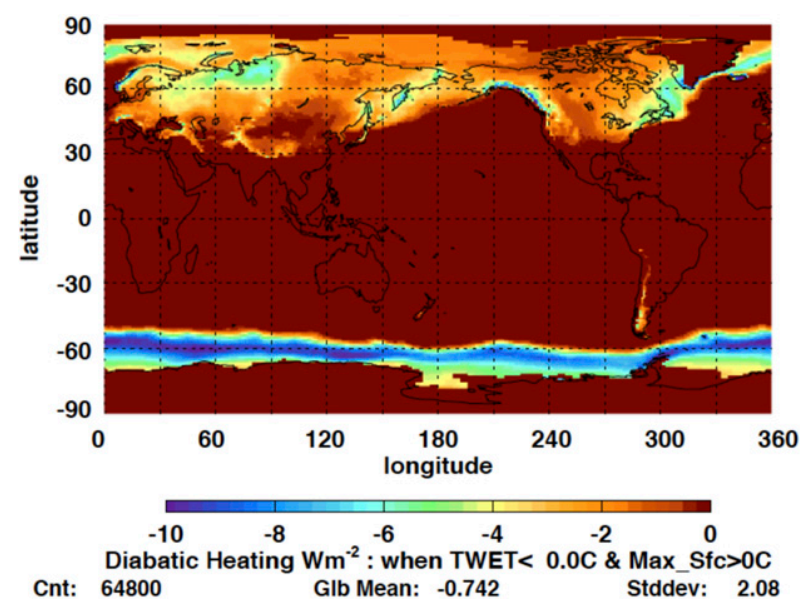

FIG. 5. Annual mean diabatic cooling rate in $\mathrm{W} \mathrm{m}^{-2}$ due to snow melt at $0^{\circ} \mathrm{C}$. The frequency of occurrence of snow is determined by the method described in appendix $F$. The global annual mean value is $-0.74 \mathrm{~W} \mathrm{~m}^{-2}$. Sixteen years of data from March 2000 through February 2016 are used.

\section{Discussion and summary}

Energy and water budget equations of the atmosphere that explicitly consider the velocity of water vapor, liquid, and ice particles, and rain and snow and their diabatic heating are formulated. Differences of the equations [Eq. (38)] derived in this study from equations used in earlier studies are 1) diabatic heating rates due to rain and snow are expressed by separate terms, 2) diabatic heating rate due to net condensation of nonprecipitating hydrometeors is included, and 3) hydrometeors can be advected with a velocity different from the velocity of dry air.

Equation (38) indicates that changing the spatial scale from global to regional to understand regional energy balance in the atmosphere increases the complexity of tracking energy flow significantly. In addition, accounting for all energy flux components in balancing regional energy requires observations that are not easily available. Equation (38) requires the knowledge of where hydrometeors are formed and how much they are transported horizontally.

Even though energy fluxes by hydrometeors in a regional energy budget are difficult to estimate, there are some observations that can be used for such an estimate. Spaceborne radar can provide vertical profiles of hydrometeors and height at which precipitating hydrometeors form (e.g., Tao et al. 2006). In addition, understanding source and sink regions of hydrometeors helps in the understanding of regional energy balance residuals when energy data products are integrated. Therefore, achieving regional water mass balance with satellite date products is necessary (e.g., Brown and Kummerow 2014). Cloud objects (Xu et al. 2005; Duncan et al. 2014; White et al. 2017) derived from high temporal observations by new geostationary satellites are also expected to help in the understanding of where clouds are generated and dissipated.

We investigated water mass balance and the effect of hydrometeor horizontal transport and diabatic heating on the regional energy budget in the atmosphere. To understand the effect of hydrometeor transport, we considered three ideal cases. When all water vapor is transported out of the column, when it forms ice crystals that are transported out, and when ice crystals subsequently fall out. At times, the energy in the atmosphere column can be more than $100 \mathrm{~W} \mathrm{~m}^{-2}$ larger from the energy in the column without ice crystal transport. The ice water content of an anvil formed in the tropics can be close to $0.1 \mathrm{~g} \mathrm{~m}^{-3}$ at a $10-\mathrm{km}$ altitude (e.g., McFarquhar and Heymsfield 1996). The water vapor concentration of a tropical standard atmosphere is about $0.1 \mathrm{~g} \mathrm{~m}^{-3}$ at $350 \mathrm{hPa}$ and can be $0.3 \mathrm{~g} \mathrm{~m}^{-3}$ when water vapor is saturated relative to ice. While the extreme condition considered here is not realistic, an additional water mass convergence, which also arises to balance regional water mass, associated with the horizontal transport of hydrometeors and diabatic heating can reduce regional energy budget residuals shown in Kato et al. (2016). Importantly, the sign of the energy budget change, to increase energy in the atmospheric column where hydrometeors are formed and exported and to reduce energy where hydrometeors are imported and evaporated, implies the correct direction to reduce the energy budget residual in the tropics.

The effect of enthalpy transport associated with water mass transfer through the atmosphere ocean boundary is to cool the atmosphere and to warm the ocean when the enthalpy is averaged over the global ocean. There is no effect of the enthalpy transport to the atmosphere and ocean combined system and the effect is independent of the choice of reference temperature, as long as the reference temperatures for the atmosphere and ocean are the same.

The enthalpy of vaporization used for the conversion of precipitation rate to diabatic heating rate depends on the temperature at which water vapor condenses. However, the temperature dependence of diabatic heating is offset by the enthalpy transferred from the atmosphere to hydrometeors and to water vapor. For a closed system in which precipitation and evaporation balances, the net effect of temperature dependence of the enthalpy of vaporization vanishes. As a result, the diabatic heating rate by precipitation computed by a constant enthalpy of vaporization at $0^{\circ} \mathrm{C}$ differs less than $1 \mathrm{~W} \mathrm{~m}^{-2}$ in the global annual mean value. The temperature threshold of melting snow to form rain does not affect diabatic heating by precipitation very much, but the phase of precipitation alters the regional atmospheric energy budget by up to $\sim 15 \mathrm{~W} \mathrm{~m}^{-2}$.

In addition to causes that might lead to an energy budget residual investigated in this study, inconsistent temperature and humidity profiles used in different products can also introduce an energy budget residual. For example, differences in temperature and humidity profiles used for surface irradiance, sensible and latent heat fluxes, and moist static energy horizontal transport computations can introduce energy balance residual. While the inconsistency can be avoided by using energy fluxes from a reanalysis product, the difference between observed TOA irradiances and TOA irradiances from some reanalysis products is at times quite large (e.g., Trenberth and Fasullo 2013; Hinkelman 2019). Although the magnitude of residual caused by inconsistent temperature and humidity profiles is unknown, closing global and regional energy budget 
will require a coordinated effort among different energy flux data providers.

Acknowledgments. We thank Drs. Peter Bannon of the Pennsylvania State University, Rupert Klein of Freie Universität, and Olivier Pauluis of New York University for providing comments on earlier versions, three anonymous reviewers for providing useful comments on the manuscript, and Dr. Rémy Roca of Laboratoire d'Etudes en Géophysique et Océanographie Spatiales for encouragement to work on this topic. The WOA 2013 V2 ocean climatology data product was downloaded from https://www.nodc.noaa.gov/cgi-bin/OC5/woa13/woa13.pl? parameter $=\mathrm{t}$, GPCP data were downloaded from http:// gpcp.umd.edu/, and SeaFlux data are downloaded from https:// data.nodc.noaa.gov/cgi-bin/iso?id=gov.noaa.ncdc:C00973. The efforts of SK, NL, FR, and DR for this research were supported by the NASA CERES project. The efforts of JF in this work were supported by NASA Award 80NSSC17K0565, and by the Regional and Global Model Analysis (RGMA) component of the Earth and Environmental System Modeling Program of the U.S. Department of Energy's Office of Biological \& Environmental Research (BER) via National Science Foundation IA 1844590. The National Center for Atmospheric Research is sponsored by the National Science Foundation.

\begin{tabular}{|c|c|c|}
\hline & APPENDIX A & $\begin{array}{l}k \\
k_{a}, k_{v}, k_{l} \\
\quad k_{i}, k_{r}, k_{s}\end{array}$ \\
\hline & List of Symbols & $k_{T}$ \\
\hline$\dot{C}_{v l}, \dot{C}_{v i}, \dot{C}_{l i}$ & $\begin{array}{l}\text { Column-integrated net conversion rates } \\
\text { from vapor to liquid, vapor to ice, and } \\
\text { liquid to ice }\end{array}$ & $\begin{array}{l}l_{v}, l_{s}, l_{f} \\
l_{v 0}\end{array}$ \\
\hline$c_{p}$ & $\begin{array}{l}\text { Specific heat capacity of moist air at } \\
\text { constant pressure including dry air, } \\
\text { water vapor, liquid particle, ice parti- } \\
\text { cle, rain, and snow }\end{array}$ & $\begin{array}{l}M_{a}, M_{a, \mathrm{sfc}} \\
m_{a}, m_{v}, m_{l}, m_{i} \\
\quad m_{r}, m_{s}, m\end{array}$ \\
\hline$c_{p_{a}}, c_{p_{v}}, c_{p_{m}}$ & $\begin{array}{l}\text { Specific heat capacity of dry air, water va- } \\
\text { por, and moist air at constant pressure }\end{array}$ & $\dot{P}$ \\
\hline$c_{v}$ & $\begin{array}{l}\text { Specific heat capacity of water vapor at } \\
\text { constant pressure } c_{p_{v}}\end{array}$ & $\dot{P}_{r}, \dot{P}_{s}$ \\
\hline$c_{l}, c_{i}, c_{r}, c_{s}, c_{\chi}$ & $\begin{array}{l}\text { Specific heat capacity of liquid particle, } \\
\text { ice crystals, rain, snow, and } \chi ; c_{r}=c_{l} \\
\text { and } c_{s}=c_{i}\end{array}$ & $\begin{array}{l}\dot{P}_{v r}, \dot{P}_{v s}, \dot{P}_{r i} \\
\quad \dot{P}_{r s}, \dot{P}_{l s}\end{array}$ \\
\hline$c_{w}$ & Specific heat capacity of liquid water or ice & \\
\hline$\dot{E}$ & $\begin{array}{l}\text { Evaporation rate of water vapor at } \\
\text { surface }\end{array}$ & $p, p_{\mathrm{sfc}}, p(0)$ \\
\hline$F_{\mathrm{SH}}, F_{\mathrm{LH}}$ & $\begin{array}{l}\text { Sensible and latent heat flux at the sur- } \\
\text { face defined positive downward }\end{array}$ & $\begin{array}{l}p_{a}, p_{v} \\
R_{\mathrm{toa}}, R_{\mathrm{sfc}}\end{array}$ \\
\hline$F_{\text {fallout }}$ & $\begin{array}{l}\text { Enthalpy flux at the surface associated with } \\
\text { water mass transport by precipitation }\end{array}$ & Toa - Salc \\
\hline$F_{v}$ & $\begin{array}{l}\text { Enthalpy flux associated with evapora- } \\
\text { tion of water vapor from surface to the } \\
\text { atmosphere }\end{array}$ & $r_{v}, r_{l}, r_{i}, r_{r}, r_{s}$ \\
\hline$F_{\Phi}$ & $\begin{array}{l}\text { Potential energy flux caused by horizontal } \\
\text { and vertical divergence of water mass } \\
\text { by water vanor and hydrometeor ve- }\end{array}$ & $\dot{r}_{v}, \dot{r}_{l}, \dot{r}_{i}, \dot{r}_{r}, \dot{r}_{s}$ \\
\hline
\end{tabular}
by water vapor and hydrometeor velocities deviating from dry-air velocity $g$

$h$

$J_{\mathrm{dif}}, J_{\mathrm{dif}, k}, J_{\mathrm{dif}, T}$

$J_{\text {fallout }}, J_{\text {fallout }, k}$ $J_{\text {fallout }, T}$

$J_{\text {fr }}$

$J_{m}$

$J_{\text {phase }}$

$J_{r}$

$$
\begin{aligned}
& J_{\mathrm{rad}}, J_{\mathrm{rad}_{m}}, J_{\mathrm{rad}_{l}}, \\
& \quad J_{\mathrm{rad}_{i}}, J_{\mathrm{rad}_{r}}, J_{\mathrm{rad}_{s}}
\end{aligned}
$$

$J_{\text {trans }}$

\section{$k$}

$k_{a}, k_{v}, k_{l}$,

$k_{T}$

$l_{v 0}$

$m_{r}, m_{s}, m$

$P_{r}, P_{s}$

$\dot{P}_{v r}, \dot{P}_{v s}, \dot{P}_{r i}$, $\dot{P}_{r s}, \dot{P}_{l s}$

$p, p_{\text {sfc }}, p(0)$

$p_{a}, p_{v}$

$R_{\text {toa }}, R_{\text {sfc }}$
Acceleration due to gravity

Enthalpy

Rate of energy change per unit mass due to diffusion, diffusion of kinetic energy, and diffusion of enthalpy

Rate of energy change per unit mass due to fallout, fallout of kinetic energy, and fallout of enthalpy

Diabatic heating rate per unit mass due to friction

Diabatic heating rate per unit mass due to radiation and conduction

Diabatic heating rate per unit mass due to water phase change

Mass flux of water vapor and hydrometeors due to their velocities relative to dry-air velocity and mixing ratio gradients

Diabatic heating rate per unit mass of dry air containing water vapor (and other absorbing gases) and hydrometeors due to radiation, absorption and emission by moist air, liquid and ice particles, rain, and snow

Diabatic heating rate per unit mass due to conduction

Kinetic energy including all constituents

Kinetic energy of dry air, water vapor, liquid particle, ice particle, rain, and snow

Thermal conductivity

Enthalpy of vaporization, sublimation, and fusion of water

Enthalpy of vaporization at $0^{\circ} \mathrm{C}$

Dry-air mass per unit area and dry-air mass per unit area at the surface

Mass of dry air, water vapor, liquid particle, ice particle, rain, snow, and $\chi$

Precipitation rate including rain and snow at surface

Precipitation rate of rain and snow at surface

Column-integrated net conversion rates from vapor to rain, vapor to snow, rain to ice, rain to snow, and liquid particles to snow

Pressure, surface pressure, and pressure at the top boundary

Dry-air pressure and water vapor pressure

Net irradiance at the top-of-atmosphere and surface

Sum of the mixing ratio of water vapor, liquid and ice crystals, rain drops and snowflakes

Mixing ratio of water vapor, liquid particle, ice crystals, rain drops, and snowflakes

Production rate of water vapor, liquid particle, ice particle, rain drops, and snowflakes per unit mass 


$$
\begin{aligned}
& \dot{r}_{v l}, \dot{r}_{v r} \\
& \dot{r}_{v i}, \dot{r}_{v s} \\
& \dot{r}_{l i}, \dot{r}_{r i}, \dot{r}_{r s}, \dot{r}_{l s}
\end{aligned}
$$$$
T
$$$$
T_{750}, T_{0}
$$$$
T_{\text {skin }}
$$$$
T_{p}
$$$$
T_{w}
$$$$
\bar{T}_{\text {atm }}
$$$$
\bar{T}_{\text {ocn }}
$$$$
t
$$$$
\mathbf{U}_{a}
$$$$
\mathbf{U}_{\chi}
$$$$
\mathbf{U}_{v}, \mathbf{U}_{l}, \mathbf{U}_{i} \text {, }
$$$$
\mathbf{U}_{r}, \mathbf{U}_{s}
$$

$\mathbf{v}_{\chi}$

$\mathbf{v}_{v}, \mathbf{v}_{l}, \mathbf{v}_{i}, \mathbf{v}_{r}, \mathbf{v}_{s}$

$w_{\chi}$

$w_{v}, w_{l}, w_{i}$,

$w_{r}, w_{s}$

$z, z(0)$

$\alpha_{\mathrm{m}}$

$\chi$

$\dot{\chi}$

$\Phi, \Phi_{s}$

$\eta$

$\rho$

$\rho_{a}, \rho_{v}, \rho_{l}$, $\rho_{i}, \rho_{r}, \rho$

$\omega_{a}, \omega_{\chi}$
Net condensation rate of water vapor to form liquid particle and rain

Net deposition rate of water vapor to form ice particle and snow

Net fusion rate of liquid particle to form ice particles, rain to form ice particles, rain to form snow, and liquid particle to form snow

Temperature of dry air, water vapor, liquid particles, ice crystals, rain drops, and snow flakes

$750-\mathrm{hPa}$ temperature and reference temperature

Surface skin temperature

Temperature of precipitating hydrometeors

Wet-bulb temperature

Mass-weighted mean temperature of the atmosphere

Mass-weighted mean temperature of the ocean

Time

Horizontal velocity of dry air

Horizontal velocity of $\chi$

Horizontal velocity of water vapor, liquid particle, ice particle, rain, and snow $=\mathbf{U}_{a}+\mathbf{v}_{\chi}$

Horizontal velocity of constituent $\chi$ relative to the dry-air horizontal velocity

Horizontal velocity of water vapor, liquid particle, ice particle, rain, and snow relative to the dry-air horizontal velocity

Vertical velocity of constituent $\chi$ relative to the dry-air vertical velocity

Vertical velocity of water vapor, liquid particle, ice particle, rain, and snow relative to the dry-air vertical velocity

Height and height of the top boundary

Specific volume of moist air

Generic flow property per unit dry-air mass

Rate of production of $\chi$

Geopotential and surface geopotential

Vertical coordinate, dry-air mass per unit area

Density of air including water vapor and hydrometeors

Density of dry air, water vapor, liquid particles, ice crystals, rain drops, and snow flakes

Vertical velocity of dry air and $\chi$

\section{APPENDIX B}

\section{Change of $\chi$ in the Dry-Air Parcel}

Equation (6) is derived in Bannon (2002) with the height vertical coordinate; the derivation in dry-air mass coordinate follows.

$$
\begin{gathered}
\mathbf{U}_{\chi}=\mathbf{U}_{a}+\mathbf{v}_{\chi}, \\
\omega_{\chi}=\omega_{a}+w_{\chi}, \\
\frac{D}{D t}\left(\frac{\chi}{\rho_{a}}\right)= \\
\frac{1}{\rho_{a}} \frac{D \chi}{D t}-\frac{\chi}{\rho_{a}^{2}} \frac{D \rho_{a}}{D t}=\frac{1}{\rho_{a}}\left[\frac{\partial \chi}{\partial t}+\nabla_{\eta} \cdot\left(\chi \mathbf{U}_{\chi}\right)+\frac{\partial \chi \omega_{\chi}}{\partial \eta}\right] \\
-\frac{1}{\rho_{a}}\left[\nabla_{\eta} \cdot\left(\chi \mathbf{v}_{\chi}\right)+\frac{\partial \chi w_{\chi}}{\partial \eta}\right]-\frac{1}{\rho_{a}} \chi\left(\nabla_{\eta} \cdot \mathbf{U}_{a}+\frac{\partial \omega_{a}}{\partial \eta}\right) \\
-\frac{\chi}{\rho_{a}^{2}} \frac{D \rho_{a}}{D t} .
\end{gathered}
$$

But

$$
\frac{\partial \chi}{\partial t}+\nabla_{\eta} \cdot\left(\chi \mathbf{U}_{\chi}\right)+\frac{\partial \chi \omega_{\chi}}{\partial \eta}=\dot{\chi}
$$

and

$$
\frac{1}{\rho_{a}} \frac{D \rho_{a}}{D t}=\nabla_{\eta} \cdot \mathbf{U}_{a}+\frac{\partial \omega_{a}}{\partial \eta}=0
$$

Therefore,

$$
\frac{D}{D t}\left(\frac{\chi}{\rho_{a}}\right)=\frac{\dot{\chi}}{\rho_{a}}-\frac{1}{\rho_{a}}\left[\nabla_{\eta} \cdot\left(\chi \mathbf{v}_{\chi}\right)+\frac{\partial \chi w_{\chi}}{\partial \eta}\right] .
$$

\section{APPENDIX C}

\section{Thermodynamic Equation}

The thermodynamic equation of moist air for a closed system is

$$
c_{p_{m}} \frac{D T}{D t}-\alpha_{m} \frac{D p}{D t}=J_{m}
$$

where $c_{p_{m}}=c_{p_{a}}+r_{v} c_{p_{v}}, c_{p_{a}}$, and $c_{p_{v}}$ are, respectively, the specific heat capacity of dry air and water vapor at constant pressure, $r_{v}$ is the water vapor mixing ratio, pressure $p$ is the sum of the dryair pressure and water vapor pressure $p=p_{a}+p_{v}$, specific volume $\alpha_{m}$ is the volume of the parcel divided by the sum of the mass of dry air and water vapor, and $J_{m}$ is the diabatic heating to moist air due to radiation, conduction, and friction. In Eq. (C1) the mixing ratio of water vapor is constant with time so that $c_{p_{m}} D T / D t$ is the enthalpy change in the parcel. In addition to the diabatic heating to the closed system that changes the enthalpy of the parcel, when the system is open, water vapor moving at a different velocity from the dry-air velocity can transport enthalpy (e.g., de Groot and Mazur 1984, p. 13) to the parcel or the enthalpy of the parcel changes when the mixing ratio of water vapor changes. Using Eq. (6) with $\chi=c_{p_{v}} T$ and combining with Eq. (C1) leads to

$$
\frac{D c_{p_{m}} T}{D t}-\alpha_{m} \frac{D p}{D t}=J_{m}+h_{v} \dot{r}_{v}-r_{v}\left[\nabla_{\eta} \cdot\left(c_{p_{v}} T \mathbf{v}_{v}\right)+\frac{\partial\left(c_{p_{v}} T w_{v}\right)}{\partial \eta}\right]
$$

where $h_{v}$ is the enthalpy of vaporization or sublimation. 
If hydrometeors are present in the parcel, then the specific volume $\alpha$ with an assumption that hydrometeors occupy no space is

$$
\alpha=\frac{V}{m_{a}\left(1+r_{v}+\sum_{i=l, i, r, s} r_{i}\right)},
$$

where $V$ is the volume of the parcel occupied by dry air and water vapor, $m_{a}$ is the mass of dry air, and $r_{i}$ is the mixing ratio of the $i$ th hydrometeor. The change of enthalpy due to hydrometeors moving at a different velocity from the dry-air velocity is given by Eq. (6) with $\chi=c_{\chi} T$ :

$$
\frac{D r_{\chi} c_{\chi} T}{D t}=J_{\mathrm{rad}_{\chi}}+h_{\chi} \dot{r}_{\chi}-r_{\chi}\left[\nabla_{\eta} \cdot\left(c_{\chi} T \mathbf{v}_{\chi}\right)+\frac{\partial\left(c_{\chi} T w_{\chi}\right)}{\partial \eta}\right],
$$

where $\chi=l, i, r$, or $s$ and $h_{\chi}$ is the enthalpy change of hydrometeor $\chi$ due to phase change. Replacing $\alpha_{m}$ by $\alpha$ and summing Eqs. (C2) and (C4) leads to

$$
\frac{D c_{p} T}{D t}-\alpha \frac{D p}{D t}=J_{\text {rad }}+J_{\text {phase }}+J_{\text {dif }, T}+J_{\text {fallout }, T}+J_{\text {trans }}+J_{\text {fr }},
$$

where

$$
c_{p}=c_{p_{m}}+r_{l} c_{l}+r_{i} c_{i}+r_{r} c_{l}+r_{s} c_{i}
$$

$r_{l}$, and $r_{i}$, are the mixing ratios of liquid and ice cloud particles, $r_{r}$ and $r_{s}$ are the mixing ratios of rain and snow, and $c_{l}$ and $c_{i}$ are the specific heat capacities of liquid water and ice; $J_{\mathrm{fr}}$ is diabatic heating due to friction. Other diabatic heating is separated into two terms due to radiation $J_{\text {rad }}$ [Eq. (20)], which is the sum of radiative heating by moist air and hydrometeors, and phase change $J_{\text {phase }}$.

Diabatic heating due to water phase change $J_{\text {phase }}$ is

$$
J_{\text {phase }}=l_{v}\left(\dot{r}_{v l}+\dot{r}_{v r}\right)+l_{s}\left(\dot{r}_{v i}+\dot{r}_{v s}\right)+l_{f}\left(\dot{r}_{l i}+\dot{r}_{r i}+\dot{r}_{l s}+\dot{r}_{r s}\right),
$$

where $\dot{r}_{v l}, \dot{r}_{v r}, \dot{r}_{v i}$, and $\dot{r}_{v s}$ are the rate of water vapor mixing ratio change due to the formation of liquid particles, rain drops, ice particles and snow, respectively; $\dot{r}_{l i}, \dot{r}_{r i}, \dot{r}_{l s}$ and $\dot{r}_{r s}$ are the rate of liquid hydrometeor mixing ratio changes due to freezing, forming ice particles and snow, respectively; and $l_{v}, l_{s}$, and $l_{f}$ are, respectively, the enthalpy of vaporization, sublimation, and fusion of water. The reverse process can occur. Therefore, a negative $\dot{r}_{v r}$ accounts for evaporation of raindrops. Other terms, $J_{\text {dif }, T}, J_{\text {fallout }, T}$, and $J_{\text {trans }}$ are given by, respectively, Eqs. (21), (22), and (23). We only treat the enthalpy flux by heat conduction $J_{\text {trans }}$ by the sensible heat flux at the surface and atmosphere boundary.

\section{APPENDIX D}

\section{Water Mass and Moist Static Energy Equations}

The equation of conservation of water mass in the parcel using Eq. (6) with $\chi=\rho_{v}+\rho_{l}+\rho_{i}+\rho_{r}+\rho_{s}$ is
$\frac{D r}{D t}=\dot{r}_{v}+\dot{r}_{l}+\dot{r}_{i}+\dot{r}_{r}+\dot{r}_{s}-\sum_{j=v, l, i, r, s}\left[\nabla_{\eta} \cdot\left(r_{j} \mathbf{v}_{j}\right)+\frac{\partial\left(r_{j} w_{j}\right)}{\partial \eta}\right]$.

Multiplying Eq. (D1) by $\rho \partial z / \partial \eta$ and integrating over the atmospheric column leads to

$$
\begin{aligned}
& \int_{M_{a, s f c}}^{0} \frac{\partial r}{\partial t} \rho \frac{\partial z}{\partial \eta} d \eta+\int_{M_{a, \mathrm{sfc}}}^{0} \nabla_{\eta} \cdot \mathbf{U}_{a} r \rho \frac{\partial z}{\partial \eta} d \eta+\int_{M_{a, \mathrm{scc}}}^{0} \frac{\partial \omega_{a} r}{\partial \eta} \rho \frac{\partial z}{\partial \eta} d \eta \\
& =-\sum_{j=v, l, i, r, s} \int_{M_{a, \mathrm{scc}}}^{0} \nabla_{\eta} \cdot\left(r_{j} \mathbf{v}_{j}\right) \rho \frac{\partial z}{\partial \eta} d \eta-\sum_{j=v, l, i, r, s} \int_{M_{a, \mathrm{sfc}}}^{0} \frac{\partial\left(r_{j} w_{j}\right)}{\partial \eta} \rho \frac{\partial z}{\partial \eta} d \eta,
\end{aligned}
$$

where $\dot{r}_{v}+\dot{r}_{l}+\dot{r}_{i}+\dot{r}_{r}+\dot{r}_{s}=0$ is used. The boundary condition of Eq. (33) is used when time and horizontal derivatives are brought outside the integrals, then Eq. (D2) is

$$
\begin{aligned}
\frac{1}{g} \frac{\partial}{\partial t} \int_{0}^{p_{\mathrm{sc}}} r d p+\frac{1}{g} \nabla \cdot \int_{0}^{p_{\mathrm{sfc}}} \mathbf{U}_{a} r d p \\
\quad=-\frac{1}{g} \int_{0}^{p_{\mathrm{sfc}}} \sum_{j=v, l, i, r, s} \nabla \cdot \mathbf{v}_{j} r_{j} d p+\dot{E}-\dot{P}_{r}-\dot{P}_{s},
\end{aligned}
$$

where $\dot{E}, \dot{P}_{r}$, and $\dot{P}_{s}$ are, respectively, evaporation, rain, and snow rate at the surface. Equation (D3) is the exact equation of water mass budget in the atmospheric column. The balance equation of moist static energy plus kinetic energy including temperature and phase dependent enthalpy can be derived by starting with Eq. (38) and adding the latent heat term used in Eq. (6) with $\chi=l_{v} \rho_{v}+l_{l}\left(\rho_{l}+\rho_{r}\right)-l_{f}\left(\rho_{i}+\rho_{s}\right)=l_{j} \rho_{j}$ :

$$
\frac{D\left(l_{j} r_{j}\right)}{D t}=l_{j} \dot{r}_{j}-\left[\nabla_{\eta} \cdot\left(l_{j} r_{j} \mathbf{v}_{j}\right)+\frac{\partial\left(l_{j} r_{j}\right)}{\partial \eta}\right] .
$$

When Eq. (D4) is formulated for water vapor and hydrometeors and added to Eq. (38), the first term on the right side of Eq. (D4) cancels with diabatic heating in the parcel $J_{\text {phase }}$ in Eq. (38) because the diabatic heating due to phase change and $\dot{r}_{j} c_{j} T$ term in Eq. (38) are balanced by the source term in (D4). Therefore once Eq. (D4) is added to Eq. (38) and integrated over the atmospheric column, we have

$$
\begin{aligned}
\frac{1}{g} \frac{\partial}{\partial t} \int_{0}^{p_{\mathrm{sfc}}}\left(c_{p} T+\Phi_{s}+k+\sum_{j=v, l, i, r, s} l_{j} r_{j}\right) d p \\
\quad+\frac{1}{g} \nabla \cdot \int_{0}^{p_{\mathrm{sfc}}} \mathbf{U}_{a}\left(c_{p} T+\Phi+k+\sum_{j=v, l, i, r, s} l_{j} r_{j}\right) d p \\
=\left(R_{\mathrm{TOA}}-R_{\mathrm{sfc}}\right)+F_{\mathrm{SH}}+F_{\mathrm{LH}}+F_{v}+F_{\text {fallout }} \\
\quad-\frac{1}{g} \int_{0}^{p_{\mathrm{sfc}}}\left[\sum_{j=v, l, i, r, s} \nabla \cdot \mathbf{v}_{j} r_{j}\left(c_{j} T+k_{j}+l_{i}\right)\right] d p-F_{\Phi},
\end{aligned}
$$

where $\sum_{j=v, l, i, r, s} l_{j} r_{j}=l_{v} r_{v}+l_{l}\left(r_{l}+r_{r}\right)-l_{f}\left(r_{i}+r_{s}\right)$ is the sum of the enthalpy change when water vapor is condensed or hydrometeors melt $\left(l_{l}\right.$ in this case is the specific heat capacity multiplied by temperature difference to the reference temperature) and $F_{\mathrm{LH}}=l_{v} \dot{E}$ is the latent heat flux at the surface. Equation (D5) is similar to the equation derived in Mayer et al. (2017) and Trenberth and Fasullo (2018) except that it uses water vapor mixing ratio instead of specific humidity and that advection terms due to water vapor and hydrometeors appear 
on the right side because they can be advected by different velocities from the dry-air velocity.

\section{APPENDIX E}

\section{Enthalpy Flux Associated with Water Mass Transfer through the Surface Boundary}

We consider the reference temperature to estimate the enthalpy transferred associated with water mass transfer in this appendix. Precipitation carries the enthalpy of $c_{w} \dot{P} T_{w}$, but the apparent enthalpy transferred from the atmosphere to ocean by precipitation is different from $c_{w} \dot{P} T_{w}$ for the following reason. When water with mass $M_{2}$, specific heat capacity $c_{w 2}$, and temperature $T_{2}$ is mixed with ocean water with mass $M_{1}$, specific heat capacity $c_{w 1}$, and temperature $M_{1}$, the temperature of the mixed water $T$ is

$$
T=\frac{c_{w 1} M_{1} T_{1}+c_{w 2} M_{2} T_{2}}{c_{w 1} M_{1}+c_{w 2} M_{2}}
$$

Therefore, the temperature change $\Delta T$ from $T_{1}$ is

$$
\Delta T=T-T_{1}=\frac{c_{w 2} M_{2}\left(T_{2}-T_{1}\right)}{c_{w 1} M_{1}+c_{w 2} M_{2}} .
$$

Rewriting (E2) gives

$$
\left(c_{w 1} M_{1}+c_{w 2} M_{2}\right) \Delta T=c_{w 2} M_{2}\left(T_{2}-T_{1}\right) .
$$

The left side is the enthalpy increase from the initial state of the system 1 with the $M_{1}$ mass by the mass transfer of $M_{2}$ and the right side is the enthalpy input. Therefore, if $M_{2}$ is mixed at the rate of $\dot{M}_{2}$ per unit area, $c_{w 2} M_{2} T_{2}$ is the enthalpy flux associated with the mass transfer. The effective enthalpy transfer is proportional to $T_{2}-T_{1}$. Similar to this example, we consider water from precipitation is mixed with water in the ocean column, dividing the ocean column into $N$ layers. The enthalpy of the ocean column is

$$
\sum_{i=1}^{N} c_{w i} M_{i} T_{i}=c_{w} \bar{T} \sum_{i=1}^{N} M_{i},
$$

where $\bar{T}=\sum_{i=1}^{N} M_{i} T_{i} / \sum_{i=1}^{N} M_{i}$ is the mass-weighted mean ocean temperature and $\sum_{i=1}^{N} M_{i}$ is the mass of water per unit area. We assume that $c_{w}$ is constant. The change of the enthalpy of the ocean column due to precipitation is

$$
c_{w} \bar{T} \sum_{i=1}^{N} M_{i}+c_{w} T_{p} M_{p}=c_{w}\left(M_{p}+\sum_{i=1}^{N} M_{i}\right)(\bar{T}+\Delta \bar{T}),
$$

where subscript $p$ indicates precipitation. Similar to the twolayer model discussed above, this leads to

$$
c_{w}\left(M_{p}+\sum_{i=1}^{N} M_{i}\right) \Delta \bar{T}=c_{w}\left(T_{p}-\bar{T}\right) M_{p}
$$

The mass-weighted mean ocean temperature changes by $\Delta \bar{T}$ due to precipitation. The above examples demonstrate that when the mass-weighted mean ocean temperature is used for the reference temperature, the flux divided by the heat capacity of the ocean is the temperature change.

\section{APPENDIX F}

\section{Conversion of Precipitation Rate to Diabatic Heating Rate}

We assume that precipitation is formed at the temperature of $750-\mathrm{hPa}$ height $T_{750}$. and that the temperature of precipitating hydrometeors is the 2-m wet-bulb temperature when they fall on the surface. The temperature of the precipitating hydrometeors changes from $T_{750}$ to $T_{w}$ and the enthalpy is provided by the atmosphere. The diabatic heating rate depends on the phase of the hydrometeors.

Precip. 1: $T_{750} \geq-10^{\circ} \mathrm{C}$ and $T_{w} \geq 0^{\circ} \mathrm{C}$ (rain at $750 \mathrm{hPa}$ to the surface)

$$
\Delta h=\left[l_{v}\left(T_{750}\right)-c_{l}\left(T_{w}-T_{750}\right)\right] \dot{P} .
$$

Precip. 2: $T_{750} \geq-10^{\circ} \mathrm{C}$ and $T_{w}<0^{\circ} \mathrm{C}$ (rain at $750 \mathrm{hPa}$ and snow at the surface. Hydrometeors cool from $T_{750}$ to $T_{w}$, freeze at $0^{\circ} \mathrm{C}$, and cool to $T_{w}$ )

$$
\begin{aligned}
\Delta h= & {\left[l_{v}\left(T_{750}\right)-c_{l}\left(T_{0}-T_{750}\right)+l_{f}\left(T_{0}\right)\right.} \\
& \left.-c_{i}\left(T_{w}-T_{0}\right)\right] \dot{P} .
\end{aligned}
$$

Precip. 3: $T_{750}<-10^{\circ} \mathrm{C}$ and $T_{w} \geq 0^{\circ} \mathrm{C}$ (snow at $750 \mathrm{hPa}$ and rain at the surface. Hydrometeors warm from $T_{750}$ to $0^{\circ} \mathrm{C}$, melt, and warm to $T_{w}$ )

$$
\begin{aligned}
\Delta h= & {\left[l_{s}\left(T_{750}\right)-c_{i}\left(T_{0}-T_{750}\right)-l_{f}\left(T_{0}\right)\right.} \\
& \left.-c_{l}\left(T_{w}-T_{0}\right)\right] \dot{P} .
\end{aligned}
$$

Precip. 4: $T_{750}<-10^{\circ} \mathrm{C}$ and $T_{w}<0^{\circ} \mathrm{C}$ (snow at $750 \mathrm{hPa}$ to the surface)

$$
\Delta h=\left[l_{s}\left(T_{750}\right)-c_{i}\left(T_{w}-T_{750}\right)\right] \dot{P},
$$

where $l_{v}$ is the enthalpy of vaporization, $l_{s}$ is the enthalpy of sublimation, $l_{f}$ is the enthalpy of fusion, $c_{l}$ is specific heat capacity of liquid water, $c_{i}$ is specific hear capacity of ice, $\dot{P}$ is the precipitation rate, and $T_{0}$ indicates $0^{\circ} \mathrm{C}$. Precipitation rate is taken from version 2.3 of the Global Precipitation Climatology Project (GPCP) data product and $T_{750}$ and $T_{w}$ are from Goddard Earth Observing System Model (GEOS) version 5.4.1. The threshold temperature of $-10^{\circ} \mathrm{C}$ is somewhat arbitrary. Roughly, cases 1 to 4 represent, respectively, warm rain, freezing rain or sleet, cold rain, and snow. We compute $\Delta h$ for all four cases using monthly mean regional $\left(1^{\circ} \times 1^{\circ}\right)$ precipitation rates and temperatures. Most rain over the tropical ocean is warm rain. Outside the tropics, most rain is cold rain (Mülmenstädt et al. 2015). Because we used monthly $1^{\circ} \times 1^{\circ}$ mean temperatures and rain rates to compute diabatic heating while temperature and rain rate are highly variable in time, we compare diabatic heating computed with monthly mean values with that computed hourly. Because the GPCP data product is monthly, we compute the difference using the Modern-Era 


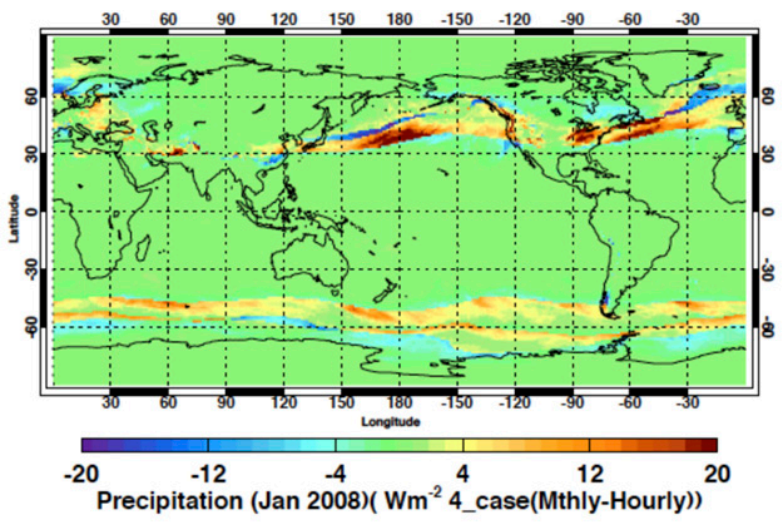

$\mathrm{N}=64800$

Glb mean(sd): 0.448 ( 3.02)

$\mathrm{Mn} / \mathrm{Mx}:-28.07 / 46.41$

FIG. F1. Difference of monthly mean diabatic heating due to precipitation in $\mathrm{W} \mathrm{m}^{-2}$. Diabatic heating rate computed hourly is subtracted from diabatic heating rate computed with monthly mean temperature and rain rate in the method discussed in appendix E.

Retrospective Analysis for Research and Applications (MERRA) in which hourly temperatures and rain rates are available using one month of data (January 2008). Figure F1 shows the difference. The difference in the global monthly mean diabatic heating is $0.4 \mathrm{~W} \mathrm{~m}^{-2}$.

\section{REFERENCES}

Adler, R. F., G. Gu, and G. J. Huffman, 2012: Estimating climatological bias errors for the Global Precipitation Climatology Project (GPCP). J. Appl. Meteor. Climatol., 51, 84-99, https:// doi.org/10.1175/JAMC-D-11-052.1.

Bannon, P., 2002: Theoretical foundations for models of moist convection. J. Atmos. Sci., 59, 1967-1982, https://doi.org/ 10.1175/1520-0469(2002)059<1967:TFFMOM>2.0.CO;2.

Bohren, C. F., and B. A. Albrecht, 1998: Atmospheric Thermodynamics. Oxford University Press, 402 pp.

Brown, P. J., and C. D. Kummerow, 2014: An assessment of atmospheric water budget components over tropical oceans. J. Climate, 27, 2054-2071, https://doi.org/10.1175/JCLI-D-13-00385.1.

Cheng, L., K. E. Trenberth, J. Fasullo, T. Boyer, J. Abraham, and J. Zhu, 2017: Improved estimates of ocean heat content from 1960 to 2015. Sci. Adv., 3, e1601545, https://doi.org/10.1126/ sciadv.1601545.

Clayson, C. A., and A. S. Bogdanoff, 2013: The effect of diurnal sea surface temperature warming on climatological air-sea fluxes. J. Climate, 26, 2546-2556, https://doi.org/10.1175/JCLI-D-12-00062.1.

de Groot, S. R., and P. Mazur, 1984: Non-Equilibrium Thermodynamics. Dover Publications, $510 \mathrm{pp}$.

Duncan, D. I., C. D. Kummerow, and G. S. Elsaesser, 2014: A Lagrangian analysis of deep convective systems and their local environmental effects. J. Climate, 27, 2072-2086, https:// doi.org/10.1175/JCLI-D-13-00285.1.

Fairall, C. W., E. F. Bradley, D. P. Rogers, J. B. Edson, and G. S. Young, 1996: Bulk parameterization of air-sea flux for Tropical OceanGlobal Atmosphere Coupled Ocean-Atmosphere Response Experiment. J. Geophys. Res., 101, 3747-3764, https://doi.org/ 10.1029/95JC03205.
Gosnell, R., C. W. Fairall, and P. J. Webster, 1995: The sensible heat of rainfall tropical ocean. J. Geophys. Res., 100, $18437-$ 18 442, https://doi.org/10.1029/95JC01833.

Held, I. M., and Coauthors, 2019: Structure and performance of GFDL's CM4.0 climate model. J. Adv. Model. Earth Syst., 11, 3691-3727, https://doi.org/10.1029/2019MS001829.

Hinkelman, L. M., 2019: The global radiative energy budget in MERRA and MERRA-2: Evaluation with respect to CERES EBAF data. J. Climate, 32, 1973-1994, https://doi.org/10.1175/ JCLI-D-18-0445.1.

Hu, Y., S. Rodier, K. Xu, W. Sun, J. Huang, B. Lin, P. Zhai, and D. Josset, 2010: Occurrence, liquid water content, and fraction of supercooled water clouds from combined CALIOP/IIR/ MODIS measurements. J. Geophys. Res., 115, D00H34, https://doi.org/10.1029/2009JD012384.

Kasahara, A., 1974: Various vertical coordinate systems used for numerical weather prediction. Mon. Wea. Rev., 102, 509-522, https://doi.org/10.1175/1520-0493(1974)102<0509:VVCSUF> 2.0.CO;2.

Kato, S., and Coauthors, 2011: Improvements of top-of-atmosphere and surface irradiance computations with CALIPSO, CloudSat, and MODIS derived cloud and aerosol properties. J. Geophys. Res., 116, D19209, https://doi.org/10.1029/2011JD16050.

_, K.-M. Xu, T. Wong, N. G. Loeb, F. G. Rose, K. E. Trenberth, and T. J. Thorsen, 2016: Investigation of the bias in column integrated atmospheric energy balance using cloud objects. J. Climate, 29, 7435-7452, https://doi.org/10.1175/JCLI-D-15-0782.1.

Lauritzen, P. H., and Coauthors, 2018: NCAR release of CAM-SE in CESM2.0: A reformulation of the spectral element dynamical core in dry-mass vertical coordinates with comprehensive treatment of condensates and energy. J. Adv. Model. Earth Syst., 10, 1537-1570, https://doi.org/10.1029/2017MS001257.

L'Ecuyer, T. S., and Coauthors, 2015: The observed state of global energy balance in the early twenty-first century. J. Climate, $\mathbf{2 8}$, 8319-8346, https://doi.org/10.1175/JCLI-D-14-00556.1.

List, R. J., 1949: Smithsonian Meteorological Tables, 6th revised ed. Smithsonian Institute, $527 \mathrm{pp}$.

Locarnini, R. A., and Coauthors, 2013: Temperature. Vol. 1, World Ocean Atlas 2013, NOAA Atlas NESDIS 73, 40 pp., http:// data.nodc.noaa.gov/woa/WOA13/DOC/woa13_vol1.pdf.

Loeb, N. G., D. A. Rutan, S. Kato, and W. Wang, 2014: Observing interannual variations in Hadley circulation atmospheric diabatic heating and circulation strength. J. Climate, 27, 41394158, https://doi.org/10.1175/JCLI-D-13-00656.1.

Lyman, J. M., and G. C. Johnson, 2014: Estimating global ocean heat content changes in the upper $1800 \mathrm{~m}$ since 1950 and influence of climatology choice. J. Climate, 27, 1945-1957, https://doi.org/10.1175/JCLI-D-12-00752.1.

Mayer, M., L. Haimberger, J. M. Edwards, and P. Hyder, 2017: Toward consistent diagnostics of the coupled atmosphere and ocean energy budget. J. Climate, 30, 9225-9246, https://doi.org/ 10.1175/JCLI-D-17-0137.1.

McFarquhar, G. M., and A. J. Heymsfield, 1996: Microphysical characteristics of three anvils sampled during the central equatorial Pacific experiment. J. Atmos. Sci., 53, 2401-2423, https://doi.org/ 10.1175/1520-0469(1996)053<2401:MCOTAS>2.0.CO;2.

Mülmenstädt, J., O. Sourdeval, J. Delano, and J. Quaas, 2015: Frequency of occurrence of rain from liquid-, mixed-, and icephase clouds derived from A-Train satellite retrievals. Geophys. Res. Lett., 42, 6502-6509, https://doi.org/10.1002/2015GL064604.

Nelson, E. L., T. S. L'Ecuyer, S. M. Saleeby, W. Berg, S. R. Herbener, and S. C. van den Heever, 2016: Toward an algorithm for estimating latent heat release in warm rain system. 
J. Atmos. Oceanic Technol., 33, 1309-1329, https://doi.org/ 10.1175/JTECH-D-15-0205.1.

Peixoto, J. P., and A. H. Oort, 1992: Physics of Climate. American Institute of Physics, $520 \mathrm{pp}$.

Rienecker, M. M., and Coauthors, 2008: The GOES-5 data assimilation system: Documentation of versions 5.0.1, 5.1.0, and 5.2.0. NASA Tech. Rep. Series on Global Modeling and Data Assimilation, Vol. 27, NASA/TM-2008-105606, 97 pp.

Satoh, M., 2003: Conservative scheme for a compressible nonhydrostatic model with moist process. Mon. Wea. Rev., 131, 1033-1050, https://doi.org/10.1175/1520-0493(2003)131<1033: CSFACN $>2.0 . \mathrm{CO} ; 2$.

Shige, S., Y. N. Takayabu, W. Tao, and D. E. Johnson, 2004: Spectral retrieval of latent heating profiles from TRMM PR data. Part I: Development of a model-based algorithm. J. Appl. Meteor., 43, 1095-1113, https://doi.org/10.1175/15200450(2004)043<1095:SROLHP>2.0.CO;2.

Starr, V. P., 1945: A quasi-Lagrangian system of hydrodynamical equations. J. Meteor., 2, 227-237, https://doi.org/10.1175/15200469(1945)002<0227:AQLSOH > 2.0.CO;2.

Stephens, G. L., and Coauthors, 2012: An update on Earth's energy balance in light of the latest global observations. Nat. Geosci., 5, 691-696, https://doi.org/10.1038/ngeo1580.

Tao, W., and Coauthors, 2006: Retrieval of latent heating from TRMM measurements. Bull. Amer. Meteor. Soc., 87, 15551572, https://doi.org/10.1175/BAMS-87-11-1555.

Trenberth, K. E., 1997: Using atmospheric budgets as constraint on surface fluxes. J. Climate, 10, 2796-2809, https://doi.org/ 10.1175/1520-0442(1997)010<2796:UABAAC $>2.0$.CO;2.
— energy transports and implications for the Hadley circulation. J. Climate, 16, 3706-3722, https://doi.org/10.1175/15200442(2003)016<3706:SPAETA $>2.0$. CO;2.

$\longrightarrow$, and $-2003 \mathrm{~b}$ : Covariability of components of poleward atmospheric energy transports on seasonal and interannual timescales. J. Climate, 16, 3691-3705, https://doi.org/10.1175/ 1520-0442(2003)016<3691:COCOPA > 2.0.CO;2.

_ , and J. T. Fasullo, 2013: Regional energy and water cycles: Transports from ocean to land. J. Climate, 26, 7837-7851, https://doi.org/10.1175/JCLI-D-13-00008.1.

— energetics formulation. J. Climate, 31, 6263-6279, https:// doi.org/10.1175/JCLI-D-17-0838.1.

,$- \ldots$, and J. Kiehl, 2009: Earth's global energy budget. Bull. Amer. Meteor. Soc., 90, 311-324, https://doi.org/10.1175/ 2008BAMS2634.1.

von Schuckmann, K., and Coauthors, 2016: An imperative to monitor Earth's energy imbalance. Nat. Climate Change, 6 , 138-144, https://doi.org/10.1038/nclimate2876.

White, R. H., D. S. Battisti, and G. Skok, 2017: Tracking precipitation events in time and space in gridded observational data. Geophys. Res. Lett., 44, 8637-8646, https://doi.org/10.1002/ 2017 GL074011.

Xu, K., T. Wong, B. A. Wielicki, L. Parker, and Z. A. Eitzen, 2005: Statistical analyses of satellite cloud object data from CERES. Part I: Methodology and preliminary results of the $1998 \mathrm{El}$ Niño/2000 La Niña. J. Climate, 18, 2497-2514, https://doi.org/ 10.1175/JCLI3418.1. 